\title{
La cultura española y el regeneracionismo liberal. El discurso de Antonio Alcalá Galiano en la Universidad de Londres de 1828 *
}

\author{
MARÍA DEL CARMEN HEREDIA CAMPOS
}

\section{INTRODUCCION}

Uno de los episodios más fascinantes de la historia política e intelectual hispana del siglo XIX, consiste en la relación que las élites liberales ibéricas tuvieron con las principales corrientes del pensamiento europeo, en general, a través de la traumática experiencia del exilio político. Desde la segunda mitad del siglo XVIII, con nombres como el de Gregorio Mayans y Siscar ', por no citar más que el caso más destacado, el

* Este preciado documento ha sido especialmente difícil lograrlo pues, a pesar de estar citado en gran parte de la bibliografía existente sobre don Antonio Alcalá Galiano, el hecho es que no se encuentra en ninguna biblioteca pública española ni está recogida en su versión íntegra en ninguna de las publicaciones sobre él existentes. En los fondos británicos tampoco hemos tenido éxito porque conociendo que se encontraba en la Biblioteca Británica, las peticiones no han logrado su obtención ni personalmente ni a través de instituciones españolas, tal vez debido al traslado de la biblioteca a su nuevo alojamiento en St. Pancras. La suerte, finalmente, premió la paciencia de la que suscribe propiciando el contacto con la profesora de la Universidad de South Bank, de Londres, la Prof." D." doña Matilde Gallardo Barbarroja, que citaba la conferencia en sus publicaciones sobre el estudio del español en Inglaterra. La profesora Gallardo contaba con su versión original y, lo que es mejor, con la buena disposición para hacerlo llegar a mis manos. Desde aquí le expreso mi agradecimiento.

Deseo también expresar mi agradecimiento al Prof. Dr. don Angel Galán, de la Universidad de Málaga, que me ha ayudado a encontrar una dirección entre las múltiples ideas dispersas que me suscitaba la conferencia de Alcalá Galiano, así como por poner a mi disposición su biblioteca particular, lo mismo que al Prof. Dr. don Florentino Portero, de la UNED, por haberme brindado la oportunidad de editar la conferencia y mostrarme su confianza en que podía realizar el trabajo de forma aceptable, cosa que desearia haber logrado.

1 Erudito español del siglo XVIII, gramático y bibliófilo en el que renacen las cualidades de los grandes humanistas del renacimiento español y autor de la obra Origenes de la lengua española escrita en 1737. 
pensamiento ilustrado hispano estaba absolutamente identificado con la renovación intelectual que vivía el conjunto de Europa. En tanto que el Antiguo Régimen consiguió mantener intactas sus estructuras, el pensamiento, que podríamos denominar «protoliberal» se mantiene en un difícil equilibrio entre sus servicios a una corona reformista y la necesidad del poder político de no afectar en lo sustancial las estructuras socioeconómicas de la España de la época. Ahora bien, como es bien sabido, la conjunción de revolución francesa, invasión napoleónica de la Península y proceso de independización de la América hispana, fractura violentamente la sociedad española del momento. Lo mejor de la intelectualidad nacional sufrirá el exilio externo o interno y se verá obligada, en no pocos casos, a proseguir sus tareas allende nuestras fronteras. José Antonio Conde, Antonio Puigblanch, Pascual de Gayangos y un largo etcétera pasarán una parte importante de su vida en países como Francia o Inglaterra. Un camino que se vieron obligados a emprender no pocos de los luchadores y políticos más ilustres que habian surgido al calor de la lucha contra el invasor francés y de los esfuerzos por crear un marco constitucional en España, como fueron Espoz y Mina, Riego, Torrijos o Argüelles, Martínez de la Rosa, Istúriz, Mendizábal, etc. Este es un episodio bien conocido y que ha generado una ingente cantidad de bibliografía, como no podía ser menos, dada su importancia 2 .

De entre tcda esta pléyade de exiliados destaca sobremanera un ilustre descendiente de un héroe de Trafalgar, don Antonio Alcalá Galiano que compartió su activa intervención en la vida política nacional con largos períodos de exilio debido a sus profundas convicciones liberales. Entre finales del segundo decenio del siglo XIX y su muerte, acaecida en 1865, no hubo movimiento político liberal que no tuviera como uno de sus actores más destacados al gaditano cuyo periodo de formación coincide con los convulsos años que van del gobierno de Godoy a la supresión de la Constitución votada en su ciudad na-

2 Para el estudio de la emigración a Inglaterra, contamos con una obra de obligada consulta como es la de Vicente LLORENS: Liberales y románticos: una emigración española en Inglaterra (1823-1834). Ed. Castalia. 2. ${ }^{3}$ ed. Madrid, 1968. Esta obra está especialmente dedicada a este episodio, aunque hay otras obras que también lo recogen formando parte de otro conjunto: del mismo Llorens: el ya clásico, El Romanticismo español. Fundación Juan March. Madrid, 1979; de Manuel MOREno Alonso: La forja del liberalismo en España. Los amigos españoles de Lord Holland 1793-1840. Congreso de los Diputados. Madrid, 1997. cap. XIII. 
tal 3. Al mismo tiempo, Alcalá Galiano dejó una extensa obra intelectual cuyo título más difundido, aún cuando no el más relevante, es la adaptación que hizo al español de la historia de España de Dunham ${ }^{4}$. Esta mixtura entre político activo y "literato", sea éste, dramaturgo, historiador o ensayista, es absolutamente prototípica de la intelectualidad europea del siglo XIX y no se circunscribe, desde luego, al mero ámbito hispano. Por no extender la relación, y si pensamos sólo en el caso británico, cuya cultura sería determinante para Alcalá Galiano, bastará recordar los nombres de Lord Macaulay o Lord Acton 5 . Por tanto, parecería que poco queda por escribir en torno a este aspecto particular de la historia intelectual hispana 6 , sin embargo, un episodio particular de la trayectoria intelectual de Alcalá Galiano nos llamó, en su momento, poderosamente la atención. Como veremos más adelante, en el breve período en que ocupó una cátedra de español en la Universidad de Londres, el ilustre exilado editó en inglés su discurso de toma de posesión formal como «Professor" de aquella institución.

El documento consta de 33 páginas y su importancia radica no sólo en el hecho de estar aún inédito en español -ciento setenta y tres años después -a pesar de ser punto de referencia en muchos estudios sobre el siglo $X \mid X^{7}$, sino en que a través de él se puede alcanzar a comprender el

3 María del Carmen HeREdiA: Alcalá Galiano como introductor de ideas liberales en España. Trabajo elaborado con una "Ayuda a la creación literaria, 1995-96" del Ministerio de Educación y Cultura, (inédito); y tema de su tesis doctoral (en curso).

4 Samuel Astley DunHAM: Historia de España desde los tiempos primitivos hasta la mayoría de la reina doña Isabel II, redactada y anotada con arreglo a la que escribió en inglés el doctor Dunham, por don Antonio ALCALÁ GaLIANO, con una reseña de los historiadores españoles de más nota, por don Juan DONOSO CORTES, y un discurso sobre la historia de nuestra nación por don Francisco MARTínez de LA Rosa. Madrid, 1844-1846.

5 Cfr. J. W. BurRows: A Liberal Descent. Victorians Historians and the English Past. Oxford, 1981. Para la confluencia durante el llamado Período Romántico entre literatura e historia, Cfr. el clásico y magnífico estudio de D. LEVIN, History as a Romantic Art., Stanford, 1959. Utiles son las apreciaciones de B. CROCE, Teorie e histoire de I'historiographie. Geneve, 1969.

6 Cfr. F. LóPEZ, «Modesto Lafuente como paradigma de la historiografia del siglo XIX: una revisión bibliográfica», Chronica Nova (Granada, 2001) (en prensa)

7 V. LloREnS: El Romanticismo... págs. 70 y 72; M. MORENO ALONSO: La forja del liberalismo... pág. 19; Carlos García BARRón: La obra crítica y literaria de don Antonio Alcalá Galiano. Madrid, 1970. págs. 105-106 y 170; Matilde Gallardo BarbarRojA: "Spanish for commercial purposes, its introduction and development in the english higher education system", en Donaire, n. ${ }^{2} 12$ Londres (2000); “Antonio Alcalá Galiano y la enseñanza del español en la Universidad de Londres", Donaire, $n .^{\circ} 5$, (1995), pág. 32; $y$ "The teaching of spanish as a foreign language at the University of Oxford" en History of Linguistics. vol. 2. (1999), pág. 232. 
esfuerzo de muchos liberales españoles por imbricar la lengua y la literatura españolas con las raices clásicas comunes a otras lenguas y culturas europeas, frente a la idea generalizada de la identificación de lo español con lo oriental, o lo que era lo mismo con falta de progreso 8 .

Nuestra intención es ofrecer al lector español la traducción al español del documento y un breve estudio que esperamos que ayude a conocer mejor el pensamiento liberal con respecto a la cultura hispana.

Empecemos por el principio de esta fascinante historia. Don Antonio Alcalá Galiano fue el primer catedrático de lengua y literatura españolas en Inglaterra -y en Europa-, elegido en 1828 para desarrollar la recién creada cátedra en la joven Universidad de Londres, hoy University College London (UCL). Leyó su discurso inaugural, titulado An Introductory lecture delivered in the University of London, el 15 de noviembre de 1828, sábado, después de haber presentado a la aprobación del Consejo su programa de trabajo. Su conferencia fue impresa por John Taylor, editor de la Universidad de Londres, el 20 de noviembre y tuvo otra edición al año siguiente.

En sus páginas introductorias, la editorial ${ }^{9}$ expone las dudas de Alcalá Galiano sobre la publicación del discurso -que él autoriza como respuesta a la petición de sus amigos que deseaban analizar con cuidado su exposición oral-, poniendo de manifiesto la preocupación del insigne liberal español ante la impresión de una conferencia imperfecta y no preparada para ser impresa. La calurosa acogida que tuvo la había achacado el autor a contar con un público afecto, y por tanto parcial, que mezclaba su espíritu crítico con las simpatías que despertaban los liberales españoles exilados a Inglaterra, no sólo por la defensa del nuevo movimiento político sino por la conmiseración con sus privaciones en el pais de acogida.

El documento, cuyo tema el autor tacha de poco interesante -calificativo felizmente desmentido durante el transcurso de su lectura-, discurre, aparentemente de forma plácida, contando las bellezas de la lengua española, en su primera parte, y el procedimiento a seguir para su enseñanza y la de la literatura española, en la segunda. $Y$ decimos "aparentemente», porque en el trasfondo de la conferencia se recogen no pocos de los puntos conflictivos dei ideario liberal volcados en la se-

8 A. GalÁN SÁnChez: Una visión de la decadencia española, la historingrafía española sobre mudéjares y moriscos. Málaga, 1991. Pág. 53-67

9 Hemos supuesto, al no venir ninguna firma. 
lección y los olvidos de los autores españoles que se van a tratar en el curso así como en el planteamiento de la formación de la lengua española o castellano.

Dividido en dos partes fundamentales, describe en la primera la belleza de la lengua española y su filiación y confluencia con otras culturas que discurrieron por nuestro solar patrio así como la validez de la impronta que dejaron en ella, y, en la segunda expone su plan de estudio sobre los autores que dieron lugar a la literatura española. Ambas materias tienen un punto de partida común que es el poema de Mío Cid 10.

Como complemento a lo anterior, defiende las satisfacciones que aporta el conocimiento de lenguas extranjeras para el espíritu y las ventajas de su aplicación práctica, acorde con la filosofía utilitaria inglesa que regía los principios fundadores de la nueva universidad. Además defendían la importancia de conocer una lengua como el español, en particular, para unos ingleses inmersos en la necesidad acuciante de dominar el idioma para poder mantener relaciones comerciales e industriales con las nacientes repúblicas de la América española emancipada, en las cuales estaban muy interesados.

10 Hay que tener en cuenta que las «jarchas", primeras manifestaciones literarias en romance español del siglo XI, no se descubren hasta 1948, en unos antiguos manuscritos encontrados en El Cairo por el hebraista Samuel Micklos Stern. Su descubrimiento arrebataba el primer puesto en la lírica románica a las Canciones de Guillermo de Aquitania, escritas hacia 1100. 


\title{
II. LECCION INAUGURAL
}

\section{OFRECIDA EN}

\section{LA UNIVERSIDAD DE LONDRES,}

El sábado, 15 de noviembre de 1828

\author{
por \\ DON ANTONIO ALCALA GALIANO, \\ PROFESOR DE LENGUA Y LITERATURA ESPAÑOLAS.
}

\section{LONDRES:}

Impresa por John Taylor, Librero y editor de la Universidad de Londres,

Calle Upper Gower, n.ำ 30

1828.

Señores:

Cuando vengo elegido para dirigirme a ustedes como Catedrático de lengua y literatura españolas, soy consciente de las dificultades de mi situación. Estas son tales, que yo me hundiría bajo su peso, si no tuviese conocimiento de la liberalidad que constituye una distinguida característica del público británico; una liberalidad que confío invada a mi presente audiencia, y que inducirá a ustedes a conferirme lo que necesito más que nada, -una porción de indulgencia mayor de lo común. El ejemplo de mis compañeros catedráticos de lenguas extranjeras, cuyas lecciones inaugurales han sido tan amablemente, $y$, en tanto en cuanto yo pueda atreverme a aventurar mi opinión, tan merecedoramente aplaudidas, para excitar en mí esperanzas y temores: porque si la favorable recepción que ellos han encontrado es altamente esperanzadora, debe ser considerado por otra parte que si ellos tuviesen algo mucho mejores títulos para ello que el orador que ahora aparece ante ustedes. En ellos, el oyente inglés tan sólo tendrá que pasar por alto algunas peculiaridades del acento, quizá algunas imprecisiones de expresión más que compensadas por las beliezas de una muy superior especie que, como ustedes la han admirado, yo me permito celebrar. En mí, temo que ustedes encuentren mayores de- 
ficiencias, y mucho menos con qué repararlas. Lo que ellos han obtenido de la justicia de la audiencia, yo debo suplicarlo de vuestra benignidad. Una gran demanda se expone ahora ante vuestra generosidad a la que ninguna de las audiencias precedentes ha tenido que responder; sin embargo, está hecha con confianza, porque estoy seguro que la extraigo de fondos que nunca serán agotados.

Como profesor de lengua española, y conferenciante sobre literatura española, una doble tarea se presenta ante mí; y será mi objetivo en la presente lección examinar sucintamente el carácter de la primera, señalando al mismo tiempo las peculiares ventajas de su estudio, y luego dar una idea general de la segunda.

Se acepta universalmente que la lengua española o castellana no tiene rival en majestuosidad y belleza. Debo señalar aqui el dicho por Carlos $\mathrm{V}$, quien es conocido por haberla designado como la más apropiada para dirigirse al mismo Dios; si no fuera porque la evidente injusticia de su juicio sobre otras lenguas, va lejos en privar su testimonio del peso que de otro modo le hubiera conferido. Para el oído de un nativo, los sonidos con que está familiarizado desde su infancia, y con los cuales están conectadas sus más tempranas costumbres y asociaciones, deben ser necesariamente especialmente encantadores; mientras que todo lo que sea áspero y tosco en ellas se escapa en gran medida a su atención. Sin embargo, estas mismas circunstancias que le convierten en un juez parcial, deberían cualificarle como un abogado capaz; y como ninguno está más implicado que él en su causa, de la misma manera ninguno es más capaz que él para encontrar y desarrollar los puntos favorables. En el caso presente, sin embargo, su laboriosidad y celo son poco requeridas. La opinión común ha reconocido la belleza de la lengua la cual es el objeto de esta conferencia; y pocas consideraciones serán, supongo, suficientes para mostrar la justicia de tal decisión.

La lengua española deriva del latín, o, mejor diría, es el propio latín corrompido y, de acuerdo con el habla común, barbarizado por las varias naciones que se han ido sucediendo como invasoras y dirigentes temporales de la península española. Algunos hombres instruidos, movidos por el deseo de decir algo nuevo, se han esforzado en vano en enlazar el presente castellano con un origen gótico; llegando tan lejos como para asegurar que es gótico latinizado, no latín goticizado. Contra esta teoría atestigua evidentemente la totalidad de la estructura de la lengua. Es cierto, que como el resto de las lenguas modernas, sin exceptuar el italiano, ha perdido las declinaciones del latín, y admite artículos y preposicio- 
nes en su lugar: pero esto puede y debe enlazarse con la pereza de los extranjeros, quienes, sin querer sobrecargar su memoria con una variedad de terminaciones, prefieren apelar al uso más conveniente de partículas indeclinables. Sin embargo, el origen latino de las preposiciones es una muestra clara de ello como en los nombres y verbos. De per los españoles han hecho por, de cum, con; de sine, sin; de in, en; de super, sobre; mientras de ha permanecido inalterado. La terminación de los sustantivos españoles y adjetivos de género femenino en la letra a es latín; la mayoria de los sustantivos y adjetivos del género masculino en la letra o está tomada de los casos dativo y ablativo de la segunda declinación. Mayor similitud aún, llegando a veces a la identidad, puede ser encontrada en los verbos de ambas lenguas. En la primera conjugación regular, el tiempo presente del verbo amare, amar -en español amar- es amo, amas, ama, amamos, amáis, aman; que es exactamente latín si otorgamos a la letra a este sonido abierto que invariablemente tiene entre todas las naciones continentales. Sería tedioso demorarse más sobre este tema; como el simple sonido del habla española será suficiente para convencer a todo el que conoce el latín (en la manera en la cual es pronunciado en el extranjero) de una afirmación, la verdad de la cual puede difícilmente ser desmentida. Pero no será inútil observar, que existen trabajos escritos por algunos españoles, que están en latín y español; y algunos que están en latín, italiano y español; sin embargo hay que confesar que su latín no es la más pura ni la más elegante descripción.

La corriente original latina en el español ha sido considerablemente dilatada por aportes derivados de otras fuentes. De su origen griego unos pocos pueden ser rastreados; $y$ de acuerdo con los eruditos etimologistas, un no desechable número de palabras hebreas y fenicias han ido incorporadas a la lengua de un pais en el que los fenicios y sus descendientes, los cartagineses, son conocidos por haber formado numerosos y poderosos asentamientos. La contribución de las antiguas lenguas ibéricas, de las cuales el actual vizcaino o vascuence deriva indudablemente, son asimismo de alguna importancia. El número de palabras góticas en la actual lengua española es todavía más considerable. La influencia de los árabes en el castellano es admitida universalmente; y además, ha sido prodigiosamente sobrevalorada. El imperio de los árabes en el sur de España fue no menos distinguido por el esplendor literario como por sus torpezas militares. Para todos los escolares árabés la página de literatura hispano arábiga se mantiene reconocida como una de las más brillantes en los anales de esta singular nación. A pesar de la diferencia de costumbres y religión entre estos guerreros conquistadores y el pueblo que mantuvieron bajo su dominio, la mezcla de 
las dos naciones parece haber sido más perfecta entre ellos y los españoles del sur que en cualquier otro país donde quiera que los musulmanes han llevado sus armas o en los que se han establecido. Ni por supuesto están las huellas de sus costumbres incluso ahora completamente desaparecidas. El que visite las provincias del este y el sur de España, fácilmente reconocerá, en los rasgos y hábitos de los campesinos de Valencia, Granada y Andalucía -especialmente en los lugares montañosos llamados Sierras- el aspecto, las costumbres, a veces la vestimenta, no infrecuentemente los sonidos de los habitantes del norte de Africa. Todavía a pesar de estas circunstancias, el número de palabras árabes en el vocabulario español es mucho menos considerable que lo que generalmente se supone. La marea de conquista que recorrió desde el sur hasta el norte pronto comenzó a retroceder, aunque no con la misma velocidad que había avanzado. La lengua de los españoles góticos todavía continuaba siendo latín corrompido; y de él, con el paso del tiempo, brotó el romance español, o lengua castellana. El poema del Cid, generalmente admitido como la más antigua composición en el español moderno ahora existente, si bien la fecha en la que está escrito no puede ser exactamente fijada ${ }^{11}$, pertenece al tiempo en que los árabes eran todavía dueños de la mejor y mayor parte de la península; $y$ yo no veo en él ninguna proporción considerable de palabras conocidas como árabes, ni de aquellos que generalmente se consideran giros árabes. De los reyes de Castilla ninguno tuvo mas relación con los árabes que Alfonso $\mathrm{X}$, denominado «El Sabio»; y en sus trabajos astronómicos y químicos es conocido por haber aprovechado para si mismo la destreza y conocimientos de eminentes profesores árabes de dichas ciencias; sin embargo este monarca, -al cual la lengua española le debe más que a cualquier otro escritor o mecenas, el cual (admitiendo a esta lengua la dignidad de ser el interprete de los actos del gobierno, no menos que por sus propios trabajos, escritos con extraordinaria elegancia para aquellos tiempos, e incluso en una época más refinada merecedora de ser llamada elegante), puede ser proclamado casi el creador del actual castellano ${ }^{12}$, , no revela ningún

11 La discutida fecha del Poema del Cid, estaba fijada por Per Abbat (en el siglo XIV), en el año 1.140, pero hoy día es más admitida la fecha de 1.245 que es la que está escrita en el ma. nuscrito, que trasladada al calendario gregoriano ofrece la fecha de 1.207. El poema pasó por siglos de menosprecio y siglos de valoración. En el siglo XIX el propio Quintana le dedicó críticas negativas y sin embargo los extranjeros como Ticknor y otros, algo avanzado el siglo, le dedican sus alabanzas. Southey lo declaraba «el mejor de los poemas épicos que hay en castellano».

12 Hasta el siglo XIII, la prosa culta se escribia en latín. Alfonso X elige una lengua romance, el castellano, y la consagra como lengua oficial y cultural con la intención de unir las distintas comunidades ibéricas en una única lengua nacional. 
síntoma fuerte de arabismo en su estilo o en su dicción. Este código de leyes, las «Partidas», recopilado bajo su dirección, y sujeto a su revisión, y del que se dice que escribió una parte, presenta todas las trazas del latín, y sólo unas pocas de origen árabe en la lengua en la cual está escrito. En el curso de mis lecciones sobre literatura española, este tema será más ampliamente discutido: baste, por el momento, con refutar este error tan extendido, el cual atribuye a los árabes una gran participación en la composición de la lengua española. Ni siquiera dejarlo creer, porque esta participación no es tan considerable como generalmente se supone, es en suma insignificante. Palabras árabes se pueden encontrar en el español moderno; y si bien algunas de ellas suenan ásperas, hay otras que puestas junto a otras derivadas del latín, no desmerecen en la comparación. Yo no creo que el río que da su nombre a la antigua Baética suene menos melodioso al oído bajo su nombre latino de Baetis, que bajo el moro de Guadalquivir, por el cual es ahora comúnmente conocido. Tal vez la palabra alarife, derivada de la lengua árabe, es más melodiosa que arquitecto, tomada del latín. Debe ser reconocido, sin embargo, que las palabras y los sonidos árabes en general resultan bastante injuriosas para la musical belleza de la lengua castellana.

Las aportaciones italianas y francesas a la lengua española merecen ser señaladas. Las primeras han sido numerosas; pero en general la gran similitud existente entre estas dos lenguas debe ser buscada en su origen común más que en importaciones modernas, aunque de estas importaciones los escritores españoles del siglo XVI y XVII dan muestra frecuentemente. La segunda ha sido tardía pero demasiado considerable; por tanto la lengua española de nuestros días está visiblemente adulterada por palabras galas, y lo que es peor, por sintaxis gala. La teoría y la práctica de los españoles modernos a este respecto están considerablemente en desacuerdo. Mientras es universalmente aceptado entre ellos que no se deben permitir tales importaciones francesas; y no sólo eso, mientras estos principios de exclusión son llevados al extremo de condenar la introducción de palabras para las cuales no se puede encontrar sustitutos en el vocabulario español, y de locuciones nuevas que surgen del estado de los modernos conocimientos, y de la influencia que las nuevas ideas y modas de pensamiento deben ejercer en el lenguaje, -es difícil encontrar un sólo trabajo español moderno el cual no abunde en palabras y giros franceses: y los españoles, acostumbrados a tomar su información de fuentes francesas, en vano tratan de infundir en sus escritos este colorido español puro peculiar de sus antiguos autores, mientras ellos constantemente se acusan unos a otros y rechazan con la misma indignación la imputación de galicismo. 
Tras este necesariamente rápido examen de las partes que componen la lengua cuya enseñanza voy a profesar, después de examinar las fuentes de las cuales procede, pasemos a considerarla en su estado presente.

Compuesto de una justa y adecuada proporción de consonantes y vocales, aunque se puede decir que predominan estas últimas, la lengua española es especialmente melodiosa y resonante. Se hace una crítica a la lengua italiana como si fuera monótona por la multiplicidad de vocales que entran en su composición, y forman la terminación de casi todas sus palabras, -una objeción en mi opinión verdaderamente injusta y originada por un perfecto desconocimiento de la prosodia italiana. A este reparo el español no está expuesto. Todos sus sustantivos y adjetivos terminan el plural en consonante $s, y$ el plural de los verbos en consonante $s$ y $n$. Hay también numerosas terminaciones en consonante en el singular de los sustantivos y adjetivos; como virtud, virtud, color, color, feliz, feliz, criminal, criminal. La segunda persona de los verbos en singular termina igualmente en consonante $s$ en todos sus tiempos excepto en el pretérito indefinido, y el presente o único tiempo del modo imperativo. Todos los infinitivos de los verbos terminan en la consonante $r$. Por los ejemplos precedentes la gran similitud, o incluso identidad, entre las terminaciones españolas y latinas se muestran claramente. Así como no es el español deficiente en terminaciones tampoco lo es en su fuerte sabor griego, como idoneos, idóneos, encantos, encantos, embelesos, embelesos.

Algunas palabras españolas están compuestas por muchas sílabas, aunque las bisílabas y trillabas son más frecuentes que las polisílabas. Algunos de los adverbios en mente, se forman con un superlativo y esta combinación verdaderamente produce palabras muy largas. Como el adverbio desatinadisimamente, que contiene nada menos que nueve silabas.

Los acentos dan, asimismo, gran variedad y belleza a la lengua castellana. En la mayoría de las palabras españolas la penúltima sílaba es la acentuada; pero en muchas, el acento se coloca sobre la última sílaba; y dáctilos, llamados esdrújulos (el sdruccioli de los italianos), no son en absoluto raros. Cambiando estos acentos el significado de la palabra es totalmente diferente. Cuando ce-le.bre, la palabra española de tres sílabas, tiene una pronunciación larga, celebré, significa, "Celebré o he celebrado"; cuando es mediana, celebre, "que yo debo o que él debe celebrar»; y cuando es corta, célebre, es un adjetivo, "famoso o célebre".

No debe ocultarse que esta belleza de la lengua que es el objeto de mi lección, está contrarrestada por algunos inconvenientes. El sonido gutural 
de $g$ antes de la $e$ y la $i$, y de $j$ y antiguamente de $x$ delante de todas las vocales, es muy duro. Lo mismo ocurre con el sonido de la $r$ doble. Y el de la $c$ delante de $e \mathrm{e} i$, y la $z$ delante de vocales, que es parecido al th inglés en thanks, theft, thick, etc., aunque no desagradable, resulta molesto cuando se repiten, como ocurre a veces demasiado a menudo. Aunque los árabes, como ya establecimos, no introdujeron gran número de palabras en el vocabulario español, sí que introdujeron algunos de sus sonidos en la pronunciación española. Tal es la fuerte aspiración gutural que ya he mencionado. Estos sonidos guturales son tan notables en el sur de España, que si se oye una conversación entre ciertos campesinos andaluces y luego otra entre moros de la vecina costa de Barbaria, que está a cierta distancia, usted puede pensar que están hablando la misma lengua; aunque al acercarse, percibirá que el acento y el tono son los únicos elementos en que se parecen el uno al otro.

Para dar a mi audiencia una idea exacta de las bellezas y faltas de mi lengua natal, no puedo resistir la tentación de presentar algunos ejemplos de hermosas frases españoles. Incluso aquellos que no entiendan su significado, serán, creo yo, forzosamente sorprendidos y encantados con sus cadencias.

En Fray Luis de Granada, uno de nuestros mejores prosistas del siglo $X V I$, encontramos la siguiente frase:

"Blandamente se allanan las grandes ondas del mar en la arena, que con grande ruido suenan y baten en las altas peñas." *

(Pie de pág.: "Those high billows of the sea, vhich roar and dash themselves with great noise against the huge rocks, are gently broken upon the sandy shore")

La belleza de las frases de Cervantes es proverbial. Señalamos la siguiente como muestra.

"La libertad, Sancho, es uno de los más preciosos dones que á los hombres dieron los cielos: con ella no pueden igualarse los tesoros que encierra la tierra, ni el mar encubre: por la libertad, así como por la honra, se puede y debe aventurar la vida." *

(Pie de pág.: * "Liberty, O Sancho, is the most valuable which Heaven ever imparted to mankind: with it, not all the treasures contained in the bowels of the earth, or plunge in the depth of the sea, can be compared: for liberty, as well as for honour, life may, and ought to be risked.m)

De Jovelianos, nuestro mejor prosista moderno, la siguiente frase no es menos bella: 
"La gloria misma de las naciones, esa gloria buscada con tan sangriento afan y poseida con tan loco entuasiamo, pasa como la claridad de un relámpago, que en la obscuridad de la noche ilumina por un momento la bóveda del cielo, para restituirla después al imperio de las tinieblas." +

(Pie de pág.: + «The glory of nations, trah very same glory sought for with such a bloodyminded earnestness, and possessed with such mad enthusiasm, passes away like the coruscations of lightning, which in the gloom of night illuminate for a moment the vault of heaven, to replate it again under the empire of darkness.")

Si pasamos de la prosa a la composición poética, la belleza de la lengua española puede ser aún más conspicua. Escuchemos, por ejemplo, una bella estrofa de Garcilaso:

"Ves el furor del animoso viento,

Embravecido en la fragosa sierra,

Que los antiguos robles ciento a ciento

$Y$ los pinos altisimos atierra;

$Y$ de tanto destrozo aun no contento,

Al espantoso mar mueve la guerra?

Pequeña es esta furia comparada

A la de Filis con Alcino airada." ++

(Pie de pág.: ++»Do yo see the rage of the fierce wind infuriated amongst the rugged mountains, whic fells to he ground by hundreds the ancient oaks and the tallest pines; and, not satisfied with so many ravages, still wages war against the frightful sea? Yet all this fury is trifling, compared with that of Phillips angry with Alcinus..")

Los versos de Villegas que siguen son de estilo diferente, y deben jactarse del mismo mérito en cuanto a sonido concierne.

"Dulce vecino de la verde selva, Huesped eterno del Abril florido, Vital aliento de la Madre Venus Céfiro blando.» *

(Pie de pág.: * "Sweet inhabitant of the green forest, eternal companion of flowery April, vital breath of Mother Venus, thou mild Zephyr.m)

Una estrofa de Moratín padre, un poeta del siglo XVIII, es igualmente sorprendentemente magnifica. Describe el efecto de una ráfaga de viento en el enorme edificio de El Escorial, y dice asi:

"Como cuando en la octava maravilla

Del grande Escorial tan celebrado,

Se mueve el coro donde el arte brilla

A impulsos de haracan (sic) desenfrenado: 
Tiembla el panteon y altísima capilla

$Y$ estupendo cimborio agigantado:

Por los claustros bramando el aire zumba

Y el pórtico magnifico retumba." +

(Pie de pág.: + "As when in that eighth wonder of the world, that Escurial so famous, the choir, where the prodigies of art shine, is shaken by the impulse of a violent hurricane: the pantheon, and lofty chapel, and stupendous and gigantic dome tremble, the wind whistles and roars through the cloister, and the magnificent portico repeats the sound.")

¿Me permitirán Uds. que termine citando algunas bellas líneas, escritas por uno de mis mejores amigos, que ha sido muy admirado por muchos de mis alumnos particulares ingleses? Son las siguientes 13:

\author{
"Encantadas riberas del Betis \\ Sacros bosques de adelfas y rosas, \\ Apacibles colinas y hermosas, \\ Ha un momento que en vos me encontré; \\ $Y$ tranquila ilustrando ese cielo \\ De Zafiro lá luna fulgente \\ Rïelar en la riza corriente, \\ Resbalando por flores miré." ++
}

(Pie de pág.: ++ «Enchanted banks of the Baetis, sacred groves of oleander and roses, peaceful and beautiful hills, - a moment ago I found myself amongst ye. And I saw the fulgent moon quietly illuminating that sky of sapphire, her light scintillating in the curled wave, and sliding over banks of flowers.")

Señores, sé muy bien que les debo una disculpa por la introducción y todavia mas por la extensión de estas anotaciones. Estoy dispuesto a admitir que es irrelevante; pero me he dejado llevar por una entusiasta parcialidad por mi país natal, lo que estoy seguro que todos ustedes sienten por el suyo propio y que por consiguiente estarían reluctantes a condenarlo. Este entusiasmo, espero, no me influenciará tanto como para exagerar la importancia del estudio de la lengua que tengo ahora el deber de enseñar ${ }^{14}$.

13 Se refiere a su amigo, Angel Saavedra, que no seria duque de Rivas hasta 1834.

14 Hasta aquí Alcalá Galiano dedica su conferencia a la exposición de la belleza de la lengua castellana; a partir de aqui, expondrá su programa de enseñanza de la lengua castellana. Nos hemos permitido dar una breve reseña de aquellos autores que van apareciendo a to largo de su exposición a los que él no haya dado un tratamiento especial, o no hayamos comentado en la fase crítica de este trabajo o, simplemente, por ser extranjeros, la dedicación de unas notas pueda favorecer la comprensión del texto. 
Sobre su importancia, sería ocioso demorarse. Todos ustedes saben que hay pocos estudios que compensen el esfuerzo realizado en ellos tan bien como el estudio de las lenguas modernas. Al lector se le abre una nueva perspectiva en el campo del intelecto humano; para el viajero es una fuente de constante placer y comodidad. Triste y desagradable es, desde luego, la situación de aquel que visita un país extranjero sin haberse familiarizado previamente con su lengua. Y esto me lleva a señalar una ventaja peculiar adicional del estudio de la lengua española. En las vastas regiones de Sudamérica, un amplio campo se abre a la empresa británica. El capital británico fluye allí como un torrente; amplios establecimientos se han formado allí por personas británicas; y aunque el primer impulso que dirigió la atención del público hacia aquellas tierras, hay que decir que se ha reducido, todavía el permanente interés con que fue creado no puede ser abandonado, no sólo eso, debe ser cultivado y fomentado. La demanda de estudiosos del español puede llegar a ser con el paso del tiempo muy extensa. A lo ancho de la totalidad de aquel vasto continente se habla la lengua española; $y$ es un orgullo para aquellos que se sienten profunda y vitalmente implicados en las glorias de esta lengua, que pueda ser la lengua común de numerosas y florecientes naciones, los cuales en tiempos venideros las ennoblecerán con sus pensamientos y las adornarán con sus escritos.

Ojalá no olviden nunca que cualesquiera que sean los motivos de sus sentimientos contra su vieja madre patria, los motivos políticos no tienen nada que ver con las ocupaciones literarias; que la lengua de Mariana y Cervantes, de León y Rioja, la lengua de la Araucana, la lengua de sus propios ancestros, no es menos una propiedad suya que de los antiguos españoles; y que en vez de adulterarla con palabras espúreas y viciarla con construcciones impropias, ellos deberían preservar su pureza impoluta y embellecerla con ornamentos bien adaptados a su carácter original.

Señores, a aquellos de mis alumnos que deseen aprender español con propósitos prácticos, les gustará saber que en mi clase de lengua, me limitaré, primero, a una enseñanza elemental, y luego a dar una idea del idioma español, conversación y redacción de correspondencia. Pero aunque mi objeto en esta clase será enseñar con fines de uso práctico, pondré cuidado en enseñar a mis alumnos a pronunciar correctamente, escribir gramaticalmente, y hablar con comodidad y profundidad. El método que piense emplear ya lo he explicado en mi declaración al Consejo y está ante el público. Es más o menos idéntico que el de mi colega, el Profesor de italiano, con cuyas observaciones concuerdo con agrado. Aquellos que deseen algo más, deben necesariamente asistir a mis lecciones 
sobre literatura española, donde, confío, encontrarán una fuente de gratificación mental.

Sobre la literatura española las opiniones están muy divididas. Ha habido quienes han declarado que es indigna incluso de una nota al paso. Nada menos que Montesquieu (aunque, a propósito, él no sabía nada de ella) llegó tan lejos como para decir que los españoles tenian un único libro bueno (refiriéndose al Quijote), y este era una sátira sobre todos sus otros trabajos. La evidente injusticia, y además el desatino extremo de tal juicio, no requiere refutación. Sin ir tan lejos, muchos críticos han declarado, que la literatura española no merece el trabajo que su estudio necesariamente requiere ; que es pobre y trivial, deficiente en espíritu y vigor, desprovista de ciencia y carente de filosofía; en resumen, que padece el estigma de la privación de libertad civil y religiosa que ha aplastado las energías innatas de los españoles.

Una opinión contraria ha sido mantenida por algunos, más favorables a la producción intelectual española, aunque ciertamente no menos errada para dar una verdadera idea del carácter de la literatura española. Es aceptado, que en las composiciones españolas el gusto oriental es reconocido universalmente; que los escritores españoles han seguido los modelos árabes de los cuales ha brotado un impetuoso, romántico e imaginativo estilo de escribir muy diferente del resto de Europa y por esta razón fuertemente interesante. Este no es, sin embargo, el carácter exclusivo de los autores españoles; dado que, entre los más correctos de ellos, el aproximarse demasiado a la imitación del latín e italiano clásicos es un defecto con el cual deben ser justamente tachados.

Hacia el final del siglo XVIII, los libros españoles rara vez se leían por extranjeros. Severas censuras fueron hechas de ellos por los críticos que los habían leído, aunque poco y muy a menudo nada en absoluto. Apologistas poco juiciosos tomaron la defensa del honor nacional y sus imperfectos trabajos no fueron muy favorables a la causa que defendían. La respuesta dada por Denina al Sr. Mason (sic) ${ }^{15}$, que, en el artículo Espa-

15 Carlo Denina, abad, literato e historiador italiano del siglo XVIII, en su graduación en teología, en 1760, dio un interesante Discorso sopra le vicende della letteratura (Discurso sobre las vicisitudes de cualquier literatura). En el caso del texto, Alcalá Galiano se está refiriendo a la polémica que desató Nicolás Masson de Morvilliers, en 1789, cuando en la enciclopedia francesa, criticó a España con su reto: «¿Qué se debe á España? Dos, cuatro, diez siglos há ¿qué ha hecho por Europa? ". Denina le respondia en la Reponse à question que doit-on à l'Espagne?, discurso leído en la Academia de Berlín el 26 de enero de 1786, haciendo una relación de las glorias de España. 
ña de la Enciclopedia francesa, había maltratado a España; el Saggio Istorico Apologetico, por Lampillas ${ }^{16}$, un jesuita español exilado, que escribió en italiano su trabajo contra Tiraboschi, Bettinelli y Napoli Signorelli ${ }^{17}$, -no son apropiados para dar una idea correcta de la literatura española.

En nuestros días los autores españoles son mas extensamente leídos en el extranjero. En Alemania, los poetas españoles son fuertemente apreciados y admirados; y frecuentemente, hasta donde yo conozco, (ya que no conociendo la lengua alemana sólo hablo de oídas) satisfactoriamente traducidos. En Francia, son todavía escasamente conocidos. Inglaterra cuenta con buenos estudiosos del español; y los nombres de Southey (miembro de la Real Academia Española, una distinción no menos honorable para él que para el docto cuerpo que fue lo bastante liberal como para otorgar este título a un extranjero); o Lord Holland ${ }^{18}$, un nombre que ningún español puede pronunciar sin fuertes sentimientos de afecto y respeto, como celoso y constante amigo de su pais; o Bowring ${ }^{19}$, el elegante traductor de varios poemas cortos españoles, y un conversador en esta lengua con señalada corrección y fluidez; o Wiffen ${ }^{20}$, quien nos ha dado una buena versión de Garcilaso; tal vez algunos más que no recuerdo en este momento, pero a los que me gustaría hacer justicia, -pueden ser señalados con orgullo como excelentes jueces de la literatura española. Y esto, señores, no puede más que inspirarme toda suerte de terribles sentimientos, sobre la consideración de cuán importante es la tarea que he asumido apareciendo frente a un público entre el que seguro se encuentran muchos jueces inteligentes que deberán emitir un juicio sobre mi trabajo, - una sentencia que sólo por benignidad podria ser favorable.

16 El abate Lampillas, Francisco Javier, pertenece al grupo de jesuitas expulsados en 1767 por Carlos III que fijaron su residencia en Italia. La obra citada en el texto, polémica, le hizo muy famoso y se tradujo pronto al español. Otros jesuitas que llegaron con él al país de César fueron el padre Juán Andrés y Esteban de Arteaga.

17 Girolamo Tiraboschi, Saveiro Bettinelli y Pietro Napoli Signorelli, criticos literarios italianos del siglo XVIII de gran erudición y polémicos en sus trabajos.

18 Henry Richard Vasall Fox, segundo Lord Holland, fue un liberal inglés de excepción que visitó varias veces España $\theta$ hizo numerosos amigos entre sus élites intelectuales, constituyéndose en uno de los mayores defensores de la causa liberal española en Inglaterra. Sobre su primer viaje a España dejó buenas imágenes en su Foreign Reminiscences, publicado en Londres, en 1850.

19 Sir John Bowring, escritor y político inglés, seguidor de Bentham, escribió Ancient Poetry and Romances of Spain, en 1824.

20 Benjamín B. Wiffen, inglés cuáquero y uno de los difusores de la Biblia en España, junto con Usoz y Borrow, fue el impulsor de la idea de publicar una colección sobre los Reformistas Antiguos Españoles, que editó Luis Usoz entre los años 1847 a 1880. 
Aquellos de mi presente audiencia que hayan leído el tosco bosquejo de mis trabajos que ha sido presentado ante el público, son conscientes de que intento examinar la literatura de España a través de sus diferentes épocas en las cuales la he dividido, en sucesión histórica. Un plan similar al seguido por mi colega el profesor de Italiano, podría encontrarse más ventajoso pero confieso que no considero nuestra literatura tan rica como para admitir la clasificación que él ha adoptado. Yo he preferido considerarla en su nacimiento, esplendor, declive, depresión y restauración, dando así ventajas de unidad a mi curso de conferencias.

Empezaré con el poema de El Cid, el primer monumento de nuestra poesía y lengua. Desearía que hubiera caído en mi lote, o debería decir mejor que desearia ser competente para tratar de los tiempos primitivos, -quiero decir, de la literatura de España en vez de la literatura del presente idioma español. La gloria literaria de mi país bajo los romanos y los árabes fue grande por supuesto. En la primera época, esta provincia del Imperio Romano que, de acuerdo con Gibbon 21 "en la persona de Trajano produjo un emperador al cual los Escipiones no hubieran rechazado como compatriota," y el cual produjo, asimismo, en Adriano y Teodosio, dos príncipes más cuyos nombres se sitúan muy alto en la lista de emperadores romanos, -dando nacimiento a una serie de escritores que tomaron con honor un lugar secundario en la literatura latina; comenzando con Julius Hyginus, el primero de los escritores españoles mecionado por Nicolás Antonio; e incluyendo los nombres de Columella. Silius Italicus, los Sénecas, Lucano, Marcial y Quintiliano. La literatura árabe es bien conocido que floreció en España. $Y$ he visto con orgullosa satisfacción, que mi colega, el Catedrático de Hebreo, menciona a los escritores españoles hebráicos como componentes de una división en el mapa de la literatura hebrea. Pero esto es una disgresión, aunque, espero que podré ser perdonado por ella; y si, como patriota, se me podría permitir echar una rápida ojeada y llamar su atención sobre estos brillantes genios, la celebración del país en el que he nacido, debo, como Catedrático de Lengua Española, dejar a mis colegas, felizmente más capaces que yo para hacer justicia sobre este tema, la tarea de explicar las bellezas y de discutir los méritos de autores, que, aunque españoles de nacimiento, ni pertenecen a la moderna historia de España ni han escrito en su lengua actual.

21 Edward Gibbon, historiador británico del siglo XVIII, escribió una obra famosa sobre el Imperio Romano, que tituló Historia de la decadencia y de la calda del Imperio Romano, en la que atribuia su disolución a la corrupción y al cristianismo. 
Con el poema de El Cid, por tanto, debo empezar; y confieso que no encuentro en él mucho que celebrar, aunque sé que hay muchos buenos jueces que defienden una opinión contraria. En este primer periodo, la literatura española, y particularmente los poetas españoles, no pueden vanagloriarse de gran novedad y sublimidad. Es la opinión del Rev. Blanco White, un buen juez en materia literaria aunque a menudo muy hostil con su propio país, que los autores españoles que florecieron antes del siglo XVI fueron generalmente juiciosos y tímidos; no como muchos han pensado, osados y románticos. Yo estoy totalmente de acuerdo con esta opinión. El código de las “Partidas» está desde luego bellamente escrito; y en el libro de Conde Lucanor se encuentran excelentes y ocurrentes situaciones. Como escritor satírico, el Arcipreste de Hita tiene muchas acertadas ocurrencias. Las cartas de Fernán Gómez de Cibdad Real son enormemente divertidas, vivaces e inteligentes; $y$, como modelo de epistolario, pueden competir con cualquier colección de cartas de cualquier lugar. Los versos de Jorge Manrique sobre la muerte de su padre son singularmente bellos, empero la suya es una belleza sobria y majestuosa no una belleza salvaje. El mayor trabajo poético de estos tiempos, El Laberinto de Juan de Mena, es igualmente responsable de la objeción de docilidad; y aunque no carente de mérito, es inferior a los versos que acabamos de citar, si es que se puede hacer la comparación entre un largo poema y una corta, aunque elegante, composición. Uno de nuestros mejores poetas vivos, Quintana, ha comparado muchos de nuestros antiguos poemas con esa vieja panoplia conservada en las armerías, la cual, aunque puede ser admirada por los amantes de las antigüedades, es totalmente ineficaz para la guerra moderna. Este juicio, aunque severo, es en muchos aspectos justo. Las baladas (o romances) de esta época constituyen una excepción, pero esta excepción debe ser calificada. El mérito de la simplicidad y de la energía ocasional y pathos realmente lo poseen; pero, en mi opinión, nuestros mejores romances tienen que buscarse entre los escritores de una época más reciente.

Al principio del siglo XVI la literatura de España adopta un carácter totalmente diferente. El renacer de los estudios clásicos, el frecuente intercambio con Italia, y el nuevo impulso que entonces recibe el intelecto humano, son consecuencia de la producción de los máximos beneficios. La escuela de escritores, a la que los autores españoles de aquellos tiempos se puede decir que pertenecian, es la que en nuestros días ha recibido la denominación de Clásica entre las naciones continentales. No podría ser de otra manera. Los grandes hombres de aquella época eran profundamente conocedores de los saberes clásicos. La empresa de la Biblia Polyglotta muestra cuan lejos fue difundido el estudio de las antiguas len- 
guas por la Península española. Arias Montano, Simon Abril, Antonio de Nebrija, Luís Vives, Francisco Sánchez de Brozas, y muchos más, fueron eminentes en estos estudios. Nuestros historiadores Mendoza y Mariana son decididos imitadores de Salustio, Livio y Tácito. Granada es completamente ciceroniano en sus frases. Garcilaso, Herrera, León, los hermanos Argensola,abundan en imitaciones de los poetas de la antigüedad. Será tarea mía hacer justicia a las bellezas de los trabajos de estos escritores, y señalar sus faltas: una de las últimas que debo apuntar aquí; a saber, una ocasional carencia de arrojo y originalidad de pensamiento; una censura que, sin embargo, no se debe extender a todos ellos, ni aplicar a todos los casos. Es fácil encontrar las causas que produjeron tan extraordinario efecto en aquellas mentes dotadas de gran energia.

Los reyes de España en aquel tiempo orientados hacia preservar la unidad de la fe, y en la medida de lo posible, la uniformidad de pensamiento, en sus dominios, y principalmente en este reino en que estaba la sede de su poder y la principal parte de su imperio en cuanto a importancia y estimación para ellos. Para llevarlo a término se estableció la Inquisición: pero el espíritu con el que nació este tribunal le hizo que se sintiera incluso en aquellos temas a los cuales su interferencia no se extendía. Servir a Dios y al Rey eran los objetivos que los antiguos españoles tenían constantemente presentes; y para conseguirlo, sabían un único camino, del que la mínima desviación de él era seguro que les conduciría a su ruina, no sólo en el venidero, sino en este mundo. No es mi asunto en estos momentos ensalzar o censurar este tipo de actuaciones: pero su influencia en la literatura, al incidir en mi terreno, merece y debe ser señalada. De ello parte el gran poder e influencia del clero español, y los estudios de los españoles se dirigieron hacia aquellos caminos que conducían exclusivamente hacia el honor y la preferencia. La teología, pero no libre discusión, llegó a ser el principal de aquellos estudios. La filosofía escolástica se cultivó también como auxiliar de la teología: la literatura cortés fue meramente tolerada, no protegida; y aunque la protección es muy inferior a la libertad en sus efectos sobre la literatura, todavía es mejor que el descuido sin libertad. Las ciencias naturales también fueron poco atendidas. Los efectos de todo esto pueden ser imaginados. Una gran uniformidad prevaleció entre los trabajos de los españoles. En aquellos temas en los que podian, sin duda sobresalieron; pero estos temas fueron por supuesto muy pocos. Hay gran belleza de estilo en sus historiadores; gran erudición en algunos de sus escritores políticos; mucho sentimiento y una fluida dicción en sus ascéticos; gran melodía y ocasional sublimidad en sus poetas, principalmente en aquellas efusiones devo- 
tas en las que sus genios, encadenados a todas partes, podrían verterse sin restricción, y en la expresión de amor, que con ellos llega a ser una especie de sentimiento devocional: pero ni los historiadores pudieron alcanzar una visión comprensiva y filosófica de sus respectivos estudios; ni sus escritores políticos entrar en los principios directivos que constituyen los fundamentos de la ciencia política (y menos aún en una aplicación de estos a los hechos que ocurren); ni desviarse los ascéticos en disquisiciones originales y elevadas sobre los principales principios de moralidad y religión; ni aventurarse los poetas sobre temas más arriesgados (como observó Quintana) que vagas moralidades y canciones amorosas mezcladas con alegorias pastoriles. Algunas instancias pueden señalarse en las cuales los españoles de esta época rompen parcialmente con estas trabas; pero el carácter general de la literatura española del siglo XVI será admitido por jueces imparciales que es como yo la he descrito.

La imitación de los Clásicos y de los Italianos llegó finalmente a su fin; y los escritores españoles llegaron a ser más originales, aunque menos puros en su gusto. Imposibilitados para impartir el vigor de la reflexión filosófica, o la energía surgida de los contenidos de la política, en sus trabajos, a menudo se perdieron en pueriles refinamientos y confundieron lo ampuloso con la exaltación; pero al mismo tiempo confiaron más en sus propias fuerzas, fueron más nacionales, naturales, y originales en su estilo de composición. Hacia la última parte del siglo XVI y el principio del siglo XVII, experimentaron nuevos caminos, y a menudo encontraron el éxito, pero en otros casos el merecido fracaso. Entonces se escribieron la mayor parte de las novelas pastoriles, en las cuales unas pocas bellezas desperdigadas pueden difícilmente compensar la falta de trama, de verdadera y eficaz caracterización del personaje y de pathos natural al describir los asuntos de pasión. La novela satírica, la primera de las cuales, Guzmán de Alfarache, fue escrita algún tiempo antes, es en mi opinión muy superior a la pastoril. Entonces escribió Cervantes Don Quijote, un trabajo que sería ocioso celebrar aquí, ya que su derecho a la admiración universal es admitido por todos. Entonces da Lope de Vega un tono nuevo al drama español. Entonces, en fin, se compusieron la mayor parte de los deliciosos romances moriscos y pastoriles, los cuales añadieron a la simplicidad de las composiciones previas de este género, muchas otras cualidades valiosas; y que, incluso cuando estaban parcialmente corrompidos por el concepto 22 , enmendaron ampliamente sus faltas, mediante la melodía de su versificación y la ligereza de su espíritu. Al mencionar los

22 Pone la palabra en italiano: concetti (refiriéndose al conceptismo, suponemos). 
trabajos de Cervantes, nuestras comedias, y nuestros romances, he tocado las tres ramas de la literatura española que son más conocidas y más admiradas por los extranjeros. Sobre sus méritos me extenderé a lo largo de mis conferencias; pero el tributo del aplauso debido a los autores de estas creaciones no me hará olvidar las menos admitidas protestas de aprobación de sus menos conocidos compatriotas.

Es en este periodo cuando las señas del gusto oriental tienen que descubrirse en las composiciones de los poetas españoles. Que esto se suscitara de su relación con autores árabes, es extremamente dudosa. Para la mayoría del pueblo español los árabes eran por aquel entonces odiados como infieles, si no despreciados como bárbaros. Los tesoros de la literatura árabe contenidos entre los muros de El Escorial no fueron expuestos a la luz hasta la publicación de la Bibliotheca de Cassiri (sic) ${ }^{23}$, editado en el siglo XVIII: pero las costumbres de la gente en el sur de España eran como arabizantes. El gusto por la hipérbole y la metáfora prevalecieron entre ellos, debido, en parte, a su antigua conexión con los orientales, en parte a la influencia de clima y hábitos de vida comunes: y los poetas que partían de la escuela italo-clásica, imprimieron a su estilo de composición el tono, y me atrevería a decir que el aroma, de su presente existencia social. El sitio de Granada fue para los españoles lo que el sitio de Troya para los griegos. Los nombres moriscos pasaron a ser entonces poéticos; $y$ en un país donde en aquel tiempo el retiro era considerado una virtud indispensable, el amante cantaba su canción de amor a su amada bajo la alegoría de un galante morisco cortejando a una dama morisca: incluso los poetas asumieron la vestimenta arábiga. La prosa se contagió de la poesía y adquirió un elevado espíritu superior, aunque frecuentemente henchida y presuntuosa.

No se puede negar que los escritores españoles del siglo XVII son motivo de grandes objeciones. Aun así en esta era florecieron hombres de gran eminencia cuyos trabajos son hoy día leídos con placer. El hombre de Quevedo, uno de los importantes autores de este tiempo, es muy bien conocido. Saavedra es indudablemente afectado, pero enormemente elegante. Moncada ${ }^{24}$ es uno de los más elegantes, -Melo ${ }^{25}$, el mejor de los historiado-

23 Miguel Casiri, orientalista sirio, llegó a Madrid en 1748 y fue nombrado bibliotecario de EI Escorial por Fernando VI, con la misión de hacer un índice de los códigos arábigos que allí había, dando lugar a lá publicación de su Bibliotheca Arabico-Hispana Escurialensis (Madrid, 17501770), de dos tomos. Fue la primera recopilación de estos textos de gran importancia para la elaboración del periodo histórico de la dominación musulmana en España.

24 Francisco de Monceda, valenciano noble, político, diplomático, militar y escritor como muchas personalidades de los siglos XVI y XVII, cuya obra histórica principal fue Expedición de los 
res españoles. Los dramaturgos de esta época no menos importantes por su excelencia que por su número. A la cabeza de ello está Calderón, del cual los críticos de una muy ilustrada nación han hecho objeto de ilimitada admiración y aplauso, sentimientos con los cuales estoy de acuerdo; aunque quizás yo no debería ir tan lejos como ellos en la aprobación del autor, ni sustentarla en aquellos pasajes en los que ellos creen los más merecedores. Fueron muchos los escritores dramáticos, contemporáneos de Calderón; y algunos de ellos le igualan en muchos aspectos ${ }^{26}$. Mencionar sus nombres sería inútil aquí; pero en mis lecciones examinaré sus respectivos méritos, y no ocultaré sus faltas. Se ha afirmado por Andrés ${ }^{27}$, quien, aunque español, escribe en italiano, y no se muestra parcial con respecto a su propio pais, que las producciones de los dramaturgos españoles exceden con mucho en número a los de otro país cualquiera. Todos estos dramas, por supuesto, no los he leído, no más que muchos de los que los citan. En esto, 10 mismo que en otros aspectos, no me considero "bibliógrafo", y despacharé rápidamente a estos autores a los cuales no considero merecedores de especial mención, y me centraré en escudriñar los méritos de aquellos que han dejado la impronta de su genio, y deberían ser estimados por haber tenido influencia en la literatura española. Sin embargo esta parte de mi tarea será extensa, y yo mismo me halago, no falto de satisfacción para aquellos que honren mi curso con su presencia.

Tengo que tratar a continuación una época triste en la historia de la literatura española. En ella, sin embargo, floreció Solís ${ }^{28}$, quien puede ser

catalanes y aragoneses contra los turcos y griegos, donde exalta las empresas de sus antepasados en Oriente.

25 Francisco Manuel de Melo, humanista y literato hispano-portugués, nacido en 1611. Intervino en la guerra de sublevación de Cataluña escribiendo luego su famosa Historia de los movimientos, separación y guerra de Cataluña (1645). Conceptista y defensor de los modernos sin romper con la tradición del siglo XVI.

26 Al margen de las simpatías de Alcalá Galiano por Calderón, es justo reconocer que fue el escritor más estudiado y exaltado por los críticos de la escuela romántica y su fama trascendió las fronteras ibéricas eclipsando incluso al gran Lope de Vega, gloria de las letras del siglo XVII.

27 Juan Andrés, valenciano de gran espíritu crítico, escribió un trabajo enciclopédico de carácter universal titulado: Deel'origine, progressi e stato attuale d'ogni Letteratura (Parma 178298), que fue traducido a todas las lenguas. Pertenece al grupo de jesuitas expulsados por Carlos III, pasando a Nápoles donde fue bibliotecario del rey.

28 Antonio de Solís y Rivadeneyra, nació en Aicalá de Henares, en 1617, y estudió derecho canónico y civil en Salamanca, teniendo como maestro a Calderón. Gozó de buena posición en la corte, donde fue secretario real de Felipe IV y también Cronista mayor de Indias, aunque luego abandonó todo por el sacerdocio. Su obra más señalada es la Historia de la conquista de México, obra en la que trata de ofrecer una visión gloriosa de las gestas españolas para paliar los momentos de pesimismo histórico español que se vivian. 
llamado el último de los escritores antiguos españoles 29 . Dejó dos comedias muy buenas y una Historia de la Conquista de México, -un trabajo muy conocido, y severamente estigmatizado por Robertson ${ }^{30}$ como la producción de un genio humano, cuya fama supera con mucho su mérito real- una injusta afirmación, que le fue devuelta a las composiciones históricas de Robertson por Mr. Southey ${ }^{31}$ quizás con igual injusticia. Es un trabajo lleno de grandes defectos, compensados con no menos bellezas; y nadie totalmente familiarizado con la lengua castellana puede leerlo sin gran deleite, admirando incluso lo que condene. Tras la muerte de este afectado pero elocuente escritor, España se sumergió en la absoluta obscuridad mental. La edad del barbarismo de la que hablo es un fenómeno singular en la historia de la mente humana. Sin una revolución, sin la irrupción de enemigos extranjeros, solamente por causas internas, todos los signos de buen gusto, y no sólo eso, incluso de sentido común, fueron completamente borracios de entre los españoles. La postración del estado como poder político, como consecuencia de causas internas, fue pareja con la postración del intelecto español. La guerra, comúnmente llamada de Sucesión, ocurrió en este tiempo, y sus efectos fueron los que se podrían imaginar. Aunque la elevación de un Borbón al trono de España fue acompañada de algunos resultados benéficos. La forma de gobierno fue algo modificada desde una a otra clase de monarquía absoluta. La Inquisición permaneció inalterable; pero devino más supeditada a la corona, y más suave en su funcionamiento. La literatura fue protegida de acuerdo con el estilo francés de la época. Dos reales academias se crearon, una de la Lengua y otra de la Historia. Un nuevo equipo de escritores renace, -no seguidores de los escritores de la Vieja España, sino franceses en sus doctrinas y en su dialecto. Luzán escribió su trabajo sobre poética, en el cual a menudo copió al autor francés, hoy olvidado incluso en Francia,

29 Frase muy similar es la de Ticknor en su Historia de la literatura...(Tomo III, pág. 97), lo que indica, unida a otras, que los trabajos literarios de A. Galiano fueron leídos atentamente por el escritor americano.

30. William Robertson, escocés moderado muy considerado por los pensadores británicos de su época, destacó en el campo de la producción histórica, que en el caso de España dio como resultado obras como Historia del Emperador Carlos V, o la muy interesante History of the Discovery and Settlement of América, donde sorprende con su punto de vista favorable sobre la colonización española.

31 Robert Southey, escritor romántico inglés nacido en Bristol en 1774, muy admirado por los escritores y políticos de su época. Su obra más importante fue una historia de Portugal que no llegó a terminar. A España vino en 1800 donde fue nombrado académico de la R.A.E.. A. Galiano dice de él que «aunque es extranjero en la Real Academia Española, sabe como pocos de literatura española". 
Le Bossu 32 . Un escritor de estilo diferente, Feijoo, un monje benedictino, emerge impulsando la lucha contra los prejuicios que prevalecían en las ciencias naturales, y contra las extravagancias de la superstición popular. Aunque totalmente desprovisto de genio, y poco más que un traductor de trabajos franceses a un español no muy puro, poseía dos cualidades no menos raras y estimables que las de genio; a saber, sentido común, y valor moral. Conocia qué estaba bien, y no se arredraba en declarar sus sentimientos. Sus trabajos fueron muy útiles, desde luego. No necesito decir que tuvo que librar muchas batallas contra los enemigos cuyo rencor estuvo en proporción con la maldad de la causa que defendían. Fue apoyado por el gobierno de una forma muy característica del estado español de aquellos tiempos. El rey publicó una declaración, manifestando que puesto que Su Majestad había tenido el gusto de otorgar su aprobación sobre los escritos del Padre Feijoo, sería totalmente inadecuado que alguien se aventurase a censurarlo.

La protección prestada a la literatura produjo algunos buenos efectos, aunque necesariamente limitada en su operatividad. Los nuevos escritores de la escuela francesa fueron taimados, faltos de espíritu, e inflexibles; pero con todas sus faltas no se podrían comparar con sus bárbaros predecesores. Una escuela mejor se creó en el seno de las universidades. Aunque los estudios en estas instituciones estuvieron lejos de ser buenos, alli se encontraba la juventud, y los buenos efectos de la asociación se hicieron notar pronto. Lo que se aprendía en las salas de conferencias se descartaba en privado; se obtuvieron nuevos libros, y nuevas luces se difundieron sobre los estudiantes. Los efectos de esto fueron visibles en los escritores españoles de finales del siglo XVIII. Entonces floreció Jovellanos, el constante patriota, el ilustrado y firme magistrado, el elegante y melódico, no menos que filósofo escritor, en cuyos trabajos la belleza de estilo, y las más deseables cualidades de profundos principios morales, en legislación, en literatura, en artes, e incluso en economía política, tan lejos como podía llegar esta ciencia en aquellos tiempos, -están felizmente combinadas y brillan con el mismo esplendor.

Trataré con más dedicación este período de la literatura española, porque es comparativamente menos conocido, y porque puede ser considerada la precursora, la Aurora de tiempos mejores. Fue un brillante amanecer; pero, jvaya! el día siguiente fue nuboso y tormentoso, y acabó

32 ¿Jaime Le Bossu? Monje benedictino francés del s. XVI que no parece que su obra tenga mucho que ver con la de Luzán. Sería extraño que A. Galiano se hubiese podido confundir con Boileau... 
en tinieblas y confusión. España estaba predestinada a pasar por dos revoluciones sucesivas, sobre las cuales no sería apropiado que yo hablase en este lugar. La mayor parte de sus hombres de letras dirigieron su atención a la política, y todos, o casi todos, naufragaron contra esa roca. Los efectos fueron fatales para el cultivo intelectual de este país. En el terreno de la literatura española muchos árboles firmes cayeron al suelo, muchas flores a punto de abrir se marchitaron en sus capullos. Algunos permanecen aún: -esperemos que puedan dar tranquilamente sus frutos, y ser rodeados de una amplia, lujuriosa, y profunda vegetación.

No piensen, señores, que evito la tarea de expresar mi opinión sobre mis contemporáneos. Ello es odioso, lo confieso; pero, sin ello mi labor sería incompleta. Yo me comprometo a ponerla de manifiesto honesta e intrépidamente, de acuerdo con mi mejor juicio, distribuyendo justicia imparcial a amigos y enemigos; y cuando yerre, errando por los más puros motivos - cediendo tal vez a los prejuicios literarios, nunca a los políticos. Actuar de otra forma sería prueba evidente de falta de respecto hacia este público por el cual tengo que ser oído y juzgado, hacia el Consejo que me ha llamado a esta cátedra, a los que debo la dignidad de mi propio carácter. Yo deseo que la menor desviación sobre este particular me sea severamente mostrada: porque si mereciese ser abrumado con su indignación, hundiría el personaje de un catedrático de Literatura en un frustrado partidista político.

Este imperfecto bosquejo de la historia de la literatura en España, que acabo de someter a mi audiencia, es al mismo tiempo un programa de mis conferencias. En ellas seguiré el mismo orden, y examinaré más ampliamente el carácter particular de cada una de estas épocas literarias. Luego seguirá un análisis de los autores que florecieron en ellas y le dieron un toque peculiar. Mis estudiantes tendrán que presentar al final del estudio de cada una de las épocas, algunos resúmenes de lo que me hayan oído. Insistiré en ser favorecido con sus propias observaciones críticas sobre los temas que se hayan tratado; y sus objeciones, cuando tengan alguna que ofrecer, serán solicitadas con interés y discutidas amigablemente. Es posible, incluso probablemente ocurra, que en algunas ocasiones el juicio del profesor tuviese que rendirse ante el del alumno; en este caso, lejos de considerarlo humillante para mi vanidad, me inspirará un justo orgullo, al mostrarme que he conseguido el gran deseo de mi ambición, es decir, el progreso de mis estudiantes.

Señores, no necesito decir que yo confío en mis alumnos para el éxito de mis trabajos. Sin esfuerzo por su parte, mi celo será vano; -animado 
por ello, incluso mis frágiles habilidades pueden ser puestas al servicio de su progreso.

Queda por explicar la utilidad de los estudios que se me ha encomendado dirigir. Debo admitir que pertenecen a los generalmente llamados de adorno. Pero no es necesario decir aquí, que en la búsqueda de una mente liberal, las elegancias de la vida, son principalmente importantes para la felicidad de la existencia social. Contra la literatura española se puede hacer una observación, a saber, que estando desconectada de la filosofía, sólo aumenta poco el acervo de conocimientos útiles. Es verdad, que aquellos españoles que son generalmente aceptados como de ánimo fuerte y mente noble, aquellos cuyas capacidades naturales son reconocidas por todos los que han visitado su hermoso país, -igual a sus mentes en fertilidad y grandeza, pero como ellos, sufriendo el deseo de cultivarse, -no les ha vuelto reconocidos en el mundo científico, ni hecho muchas importantes contribuciones a los más altos y más útiles departamentos de filosofía política, moral o natural. Que sus intelectos son apropiados a aquellos propósitos, es fácil probarlo; e Inglaterra tan justamente orgullosa de su preponderancia en la ciencia náutica, conocerá que el nombre de Mendoza ${ }^{33}$, un español, permanece a la cabeza de la lista de autores por cuyos escritos esta ciencia es enseñada al marino inglés. España fue el primer país que podría alardear de un conjunto de cartas marítimas, regular, científico, correcto y completo, de sus costas y puertos. Pero es la desgracia de este país, que los hombres científicos que ha producido no sean conocidos fuera, y apenas conocidos entre sus propios compatriotas; porque la falta de público lector les ha desanimado de escribir $y$, cuando han escrito, han privado sus trabajos del interés con que los iniciaron. De este modo el país que ha añadido el continente e islas de América al mundo conocido y ha contribuido tan importantemente al avance de la ciencia en general, es acusado de no haber hecho nada por los intereses de la civilización.

No piensen, señores que, influenciado por una parcialidad natural, estoy intentado probar que España debería ser considerada al nivel de Italia en cuanto a conocimientos científicos. No; tan querido como es mi país

33 Sin duda se refiere a don José de Mendoza y Ríos, marino, astrónomo y escritor español del siglo XVIII. Fue encomendado para adquirir mapas y obras extranjeras para formar la biblioteca de la Marina y a su vuelta, en 1800, maltratado por España, se estableció en Inglaterra donde siguió escribiendo y publicó, entre otras obras famosas, su Colección completa de tablas para la navegación y astronomía náuticas (Londres, 1805-09), considerada la mejor obra científica del momento por ingleses y franceses. 
para mí, todavía es más querida la verdad. Al hablar sobre la literatura española, he aludido a algunas causas que han tenido influencia sobre su estado pasado y presente. Sobre la ciencia, esta influencia fue mucho más grande. ¿Qué podría hacer un hombre por los conocimientos científicos viviendo en un país donde las instituciones políticas eran casi exclusivamente calculadas para impedir y retrasar sus progresos?

Pero ¿hay que suponer que porque haya pocos trabajos de utilidad general escritos en español, hay que olvidar el estudio de los buenos historiadores españoles, novelistas o poetas? Los trabajos científicos son como esos árboles que trasplantados fuera de su suelo natal, todavía florecen y dan sus frutos; pero los productos de la imaginación, que debe parte de su mérito a la belleza de su estilo, son como esos frutos tiernos que pierden su belleza y aroma tan pronto como son arrancados del único suelo donde pueden crecer y madurar. Solamente a Inglaterra corresponde la gloria de haber creado a Bacon y Newton; pero de los tesoros contenidos en sus trabajos pueden participar todas las naciones. Shakspeare (sic) y Milton, sin embargo, sólo pueden ser comprendidos cuando se leen en la lengua que ellos han adornado. Los trabajos científicos españoles pueden igualmente ser leídos tanto en traducciones como en original: pero ¿quien puede entender Don Quixote, a menos que esté versado en la lengua en la cual está escrito?

Esta es una fuerte razón, por la cual el estudio del español, o déjenme decir, de la literatura extranjera en general, es recomendable. Esto ya lo han indicado mis colegas, los catedráticos de lenguas extranjeras; pero incluso su elocuencia me ha dejado algo que decir sobre tan rico tema. Por medio de este estudio, no sólo se dispersan los prejuicios, sino que se crean fuertes afectos. Las naciones no sólo dejan de odiarse, sino que empiezan a estimarse y amarse entre ellas. Como consecuencia, la mayor bendición del hombre social, se promueve; y la guerra, el más amargo enemigo, se desanima en la misma proporción. Los tiempos presentes nos ofrecen más de un ejemplo que prueba que esto no es un pensamiento visionario. El intercambio de producciones literarias está llegando a ser tan libre y vital como el tráfico de productos manufacturados. La fama literaria, como la felicidad política de un estado, ya no se considera perjudicial para sus vecinos. El Canal de la Mancha no se mira meramente como una zanja para proteger su tierra de ataques extranjeros, sino como una libre y conveniente avenida para importar y exportar. El aplauso con que se aclama el genio de Shakspeare (sic) y la habilidad de los actores ingleses en Paris, produce un eco recíproco en los teatros de Londres, donde los grandes maestros del drama francés, y los eminentes 
profesores del escenario francés, no son menos entusiásticamente aplaudidos. Al mismo tiempo un individuo que, como se ha hecho hace algunos años por uno de los más grandes hombres ingleses que jamás se han producido, aventurase designar a Francia como el enemigo natural de Inglaterra ${ }^{34}$, no sería menos culpado por su falta de caridad, que ridiculizado por su absurdez. El cosmopolitismo no puede ser censurado pretendiendo reemplazar nuestros afectos naturales, domésticos y patriotas con un vago amor por la generalidad del género humano, ya que se ha encontrado que los intereses privados y los generales son casi los mismos; y la caridad, sin dejar de ser una excelsa virtud, no es, en la mayor parte de los casos, sino otro nombre para el sentido común universal. De este modo, la literatura actúa sobre la política y la moral, y está a su vez es influida por ellas. No puedo dejar de pensar que el Consejo de esta Universidad actuó bajo esta impresión cuando pensó en incluir la lengua y literatura de las naciones extranjeras en la enseñanza impartida entre estos muros. Haciendo lo cual, se adapta a sí mismo al espíritu de los tiempos. Esta innovación era altamente beneficiosa para una institución diferente de todas las de su especie, tanto como la época en la que ha sido fundada difiere de las épocas precedentes. El espíritu de los tiempos es un término que ha sido ridiculizado por muchos críticos superficiales que afectan negar su existencia, sin embargo, hay varios síntomas que muestran que su incredulidad no es más que humo inútil; «A que ellos creen, lo que temen". Este espíritu, señores, esta "insustancial nada" se ha incorporado a la presente Institución y ha encontrado en ella una «un lugar propio y un nombre». No piensen que estoy haciendo un panegírico del cuerpo al que tengo el honor de pertenecer: estoy simplemente diseccionando y analizando su naturaleza y sus fines, en tanto conduzca a dilucidar el punto de vista bajo el que considero, y deseo que ustedes consideren, la débil parte, de las tareas generales, que yo debo sustentar. Repito, que esta institución es una notable creación de este país y de la era presente; y esto en ningún país como en este, donde la libertad práctica es tan extensamente disfrutada, y en ningún momento como en el presente, cuando los conocimientos son tan ampliamente difundidos, podría haber sido llamada a existir. Ha sido fundada por personas particulares de distintos rangos, objetivos, vocaciones y modos de pensar, sin otra atadura que la tarea de mostrar su celo en promover la educación liberal.

34 Puede referirse a la opinión expresada por el inglés Fox (Lord Holland), considerando a Francia el "the unalterable enemy of England", cuando se llevaba a cabo por William Pitt la firma de un tratado con aquel país, a lo que el primer ministro contestó: "to suppose that any nation could be unalterably the enemy of another is weak and childishm. 
No depende del patronazgo de ningún gobierno o partido, sino de la sencillez y el sentido común del pueblo en su conjunto. Debe, por consiguiente, mantenerse o caer por sus propios méritos, y no pedir otros favores que permitírsele un juego limpio. Aunque está dedicada a formar científicos y profesionales no menos que elegantes eruditos, muestra el modesto porte y el aspecto funcional de una sociedad mercantil. No se trata de un monopolio, pues ya se ha fundado una rival 35 motivada, se espera, por un noble espíritu de emulación, con la cual debe competir por la palma del triunfo en competición libre y honorable. Sus puertas están abiertas a los hombres de todos los credos, todos los rangos y todos los partidos. Apoya sus reivindicaciones al título que ha adoptado, no en la multitud de edificios que contiene, sino en la universalidad de la instrucción que aborda. Y aunque finalmente, pero no por ello menos importante, para hacer sus bases más anchas y más amplias que las de todo el actual conjunto de establecimientos de la misma clase, y hacerse merecedora de una época caracterizada por los sentimientos de amistad y libre comunicación existentes entre varias naciones del mundo civilizado, -ha admitido en sus recintos a catedráticos extranjeros de todas esas naciones, para enseñar sus diferentes lenguas y transmitir los méritos de la producción de sus respectivos autores eminentes; contribuyendo de esta manera al impulso de estas simpatías sociales y extensos beneficios que ofrecen campo para secar muchas de las fuentes de calamidades de las naciones, y realizar en una gran extensión este alto alarde de literatura hasta ahora sólo parcialmente real, a saber, que ablanda las costumbres de la humanidad y no deja lugar para la ferocidad- "Emollit mores, nec sinit esse feros. ${ }^{36}$,

Señores, puedo ser tachado de demasiado entusiasmo: estas consideraciones, me temo, se encontrarán demasiado elevadas; sin embargo, sentiría abandonarlas ya que haciéndolo así mis alumnos y yo mismo estaríamos seguros de perder parte de los beneficios que se derivan de la instrucción que tengo el deber de impartir. Mientras más alto pensemos sobre los objetivos en que estamos comprometidos, más preparados estaremos para seguirlos con alegría y éxito final. Bajo la impresión de estas consideraciones, mi trabajo adquiere mayor importancia ante mi vista y me acerco más al nivel de los deberes de mi situación. Considero que mientras yo estoy enseñando la lengua española y dando lecciones de literatura española, no estoy realmente descendiendo a elegantes bagate-

35 Se refiere al King's College.

36 La traducción literal sería: «Ablanda las costumbres y no permite que sean fieros» 
las, sino ejecutando una tarea que, como parte de un gran sistema, tiende hacia el gran fin de la utilidad, el objetivo al cual todos los trabajos humanos deberían estar orientados. Considero que sirvo a los mejores intereses de la humanidad en general, y más especialmente aquellos de mi país natal al cual quiero y siempre querré, pero al que quizás esté condenado a no ver más. Creo finalmente, que me estoy haciendo útil, y tanto como puedo, pagando la gran deuda que tengo con esta tierra de hospitalidad, donde he encontrado una segunda patria y he obtenido la envidiable distinción de aparecer ante ustedes en mi actual calidad, y la de haber conectado mi humilde nombre con el de la Universidad de Londres. FIN. 


\section{COMENTARIO CRÍTICO}

\section{Alcala Galiano y el liberalismo español}

Si seguimos el curso que nos marca su fascinante autobiografía entenderemos mejor el contexto del que surge una personalidad tan peculiar ${ }^{37}$. Nacido en Cádiz, el 22 de junio de 1789, en el seno de una familia ilustre y acomodada, encabezada por un gran marino que circunnavegó la tierra con la expedición de Malaspina y murió heroicamente, en 1805, en la desafortunada batalla de Trafalgar: don Dionisio Alcalá Galiano. Su madre, también de instruida familia de marinos, fue doña Consolación de Villavicencio, emparentada con el duque de San Lorenzo y la marquesa de Mena entre otros títulos. El joven Antonio admiró a su padre y adoró a su madre, pero a quién debió mucho fue a su tía materna, que vivió con ellos siempre y estuvo a su lado más que ninguna otra mujer de su vida, acompañándole, incluso, y a pesar de su edad, en su destierro a Inglaterra y Francia, muriendo a los 82 años, cinco después de reintegrarse a la España de la Regencia. Completaban el entorno familiar de Alcalá Galiano otros hombres importantes; sus tíos, en general marinos o militares con algunas excepciones hacia el mundo de las leyes o la política y bien situados en la corte, lo que colaboró a que la infancia y adolescencia de Antonio se repartiese entre la floreciente Cádiz y la corte de Madrid o Aranjuez.

Su formación infantil fue esmerada, a pesar de que, por no contar con buena salud, no acudió a la escuela quedando esta labor en manos de su madre y su abuela, mujeres muy cultas, que lo instruyeron en la historia de España, la poesía y el teatro e incluso lo iniciaron en la atención a los

37 Aunque sobre la vida de Alcalá Galiano hay varios trabajos y de variados estilos, para exponer su trayectoria familiar y sus actividades contamos con un libro inapreciable que recoge sus vivencias y pensamientos, escrito por él mismo en su ancianidad, titulado Memorias, y también sus Recuerdos de un anciano, recopilación de artículos para el diario "La América", publicados a partir de 1861, recopilados y publicados por su hijo, unos años después de su muerte. Hemos utilizado la edición de la B.A.E., tomos LXXXIII y LXXXIV, Madrid, 1955, con una buena introducción de Jorge Campos. De menores dimensiones son sus Apuntes para la biografia del Excmo. Sr. D. Antonio Alcalá Galiano, escritos por el mismo, Madrid, Imprenta del Colegio de Sordomudos y Ciegos, 1865, que tienen la peculiaridad de ser unos apuntes autobiográficos que el propio Galiano entregó a un amigo, Manuel Ovilo y Otero, para que los publicase tras su muerte. Una amplia biografía, aunque algo superficial en el tratamiento, es la de Felipe Ximenez de Sandoval Antonio Alcalá Galiano (el hombre que no llegó) Madrid, Espasa-Calpe, 1948, que, sin embargo, cuenta con el mérito de ser la primera en ocuparse, en el siglo $X X$, del insigne político del $\mathrm{XIX}$. 
sucesos políticos. Con la idea de preparar su carrera, por mediación de su tío fue inscrito con siete años como cadete de las Reales Guardias Españolas y si en algún momento pasó por la cabeza de su padre la idea de incorporarlo a la marina ésta se esfumó tras un breve viaje que ambos realizaron juntos cuando tenía trece años y disfrutaba de licencia en su batallón 38 .

En el aspecto político, las simpatías de su familia se dirigían, en el caso de su madre y sus tíos hacia los ingleses, por lo que eran llamados "mamelucos" como se llamaba a los partidarios de los ingleses, y no estaban definidas en el caso de su padre que, admirando la marina inglesa, no se identificaba como mameluco ni tampoco era un apasionado de los franceses. Fruto de este ambiente ya Antonio empieza a definirse como mameluco "acérrimo y pertinaz", mostrando la admiración por los ingleses que, con sus reservas, mantendria toda su vida. Joven instruido en Cádiz, ciudad que no habían logrado ocupar las tropas naapoleónicas y que destacaba intelectual y económicamente con respecto al resto de las provincias españolas por su comercio con ultramar y Europa, pronto se introdujo en los círculos literarios más avanzados y empezó a relacionarse con personajes reconocidos en las letras, como José Joaquín de Mora y otros mucho mayores que él, que inicia esta fase con tan sólo 16 años. Es la época de la creación con sus amigos de la "Academia de Bellas Letras", donde se inicia en las justas literarias 39.

Muere su padre en la batalla de Trafalgar, en 1805, y su madre, mediante la influencia de sus tíos Alcalá Galiano, intenta lograr para él un destino bien remunerado en Madrid, pero no lo consigue y pasa dos años en la corte sin ser militar ni seguir otra carrera; buena vida que sí le iba a proporcionar nuevos e interesantes conocimientos literarios y cortesanos. En el ambiente literario conoció al poeta Manuel José Quintana que celebraba tertulias a las que acudían Blanco-White, Juan Nicasio Gallego, Jerónimo de la Escosura y otras veteranas figuras de las letras, aunque sus amigos,

38 Embarcó con su padre en el Bahama, navío del que era capitán don Dionisio, acompañándole a Nápoles para recoger a la infanta de Nápoles para su boda con el príncipe de Asturias, el futuro Fernando VII, así como al príncipe heredero del cetro de las Dos Sicilias, que se iba a casar con la infanta Isabel. Después de este viaje, don Dionisio decidió apartar a su hijo de la marina, declarando que era un oficio mal pagado, en aprecio, con respecto al esfuerzo que requeria. Bien es verdad, que en aquel viaje el joven Antonio causó algunos problemas con sus charlas antirreligiosas y otras actitudes juveniles, aunque esto lejos de provocarle el rechazo lo que le proporcionó fue la popularidad entre la tripulación. Memorias... Tomo LXXXIII, pág. 284.

39 A. Alcalá Galiano: Recuerdos ..., pág. 5. La Academia duró de 1805 a 1808 y estuvo protegida por militares y políticos gaditanos de alto nivel. 
realmente, los escogió entre otros más jóvenes y levantiscos, aunque cultos. Es el momento en que conoce a José María Torrijos, en la Casa de Pajes del Rey, a Manuel Tovar, Cadete de las Reales Guardias, a Martín de los Llanos y a José Robles con los que se reunía en el café El Angel (hoy El Espejo) o en tertulias caseras. En una de estas tertulias cortesanas conoce a su primera mujer, María Dolores Aguilar, con la que se casó en secreto a los diecinueve años, manteniendo un matrimonio bastante tormentoso.

Al empezar la guerra de la Independencia, se traslada a Cádiz donde su contacto directo con la política se lo proporcionan las sesiones de las Cortes que se celebraron en la Isla de León y en Cádiz en 1810 y 1811 a las que asiste como espectador. Se afilia por entonces al partido liberal convirtiéndose en poco tiempo en uno de los más fervorosos defensores de la nueva doctrina, exponiendo sus ideas sobre los derechos del hombre, asimiladas de su admiración hacia al Asamblea constituyente de Francia, o la composición de las Cortes en La Tertulia y en El Redactor general y conoce personalmente a Martínez de la Rosa y a José García de León y Pizarro que influyó no poco en su formación literaria 40 . En 1812, consigue su tío Villavicencio un puesto para él en la carrera diplomática como agregado a la embajada española de Londres pero no llega a partir y se queda en España como oficial en la Secretaría de Estado de la que salió al año y medio no sin algo de escándalo por haber atacado, desde El Imparcial, los excesos de la Regencia y su connivencia con el gobierno inglés y el marqués de Wellington ${ }^{41}$. En 1813, le ascienden a secretario de la legación de España en Estocolmo, por mediación de sus tíos Villavicencio, y antes de salir para su destino ingresa en los masones ${ }^{42}$, donde ya militaban Istúriz, Carnerero y Mejía, afiliación que además de unir a sus componentes en una ideología, era considerada una «hermandad" beneficiosa para moverse por países extranjeros.

Pero tampoco en este destino, logra asentarse el joven Galiano 43 y después de tres años de graves problemas de salud e, incluso, rechazo

40 A. Alcalá Galiano: Memoria, Tomo LXXXIII, pág. 370-71.

41 Escribe en El Imparcial de vida corta: un mes, junto con un nuevo amigo Santiago Jonama, admirador ferviente de todo lo inglés, a saber, su sentido de las leyes, la aristocracia y la libertad, que transmitió en alguna medida al joven Galiano. A. Alcalá Galiano: Memorias, Tomo LXXXIII, Pág. 392.

42. Hacia mediados de 1819 se crea el "Taller Sublime", cuerpo entre el supremo masónico, - Soberano Capítúlo, y las logias, y Alcalá Galiano se alista en él como Orador. Cuando en 1821, la masonería se escinde en masones y comuneros él permanece en los primeros. A. Alcalá Galiano, Memorias, Tomo LXXXIII, pág. 461

43 Así era conocido, incluso, a veces, como "Galeano". 
por parte de algunos diplomáticos, decide incorporarse al escenario político de su patria donde pasa por una época de "vida alegre», producto de otra "vida triste» provocada por su enfermedad, su separación matrimonial y la muerte de su madre. Sin embargo, el escenario político había cambiado radicalmente durante su estancia en el extranjero. Abolida la Constitución, disueltas las Cortes y presos sus principales diputados, se ve impelido a escribir cada vez más comprometido. En el aspecto literario se reúne de nuevo con su amigo José Joaquín de Mora con el que sostiene la famosa "querella calderoniana» desde el periódico Crónica Cientifica y Literaria enfrentándose literariamente a Juan Nicolás Böhl de Faber.

El siguiente destino será como secretario de la embajada de Brasil, pero al ir a embarcarse en Cádiz, encuentra la plaza en ebullición, con la expedición para ultramar que no queria embarcar, los masones conjurados para derribar a Fernando VII y los militares, entre los que se contaba Riego aún no famoso, dispuestos a dar el golpe de mano militar. Decide intervenir activamente y empieza una carrera desenfrenada organizando los contactos entre los conjurados refugiados en Gibraltar y los de Cádiz, visitando las logias, y defendiendo él la insurrección desde La Gaceta patriótica del ejército nacional de San Fernando 44 , redactada junto con Evaristo San Miguel, propiciando, así, el levantamiento y triunfo de Riego en Las Cabezas de San Juan, que daría paso al restablecimiento de la Constitución y al Trienio Liberal con los antiguos liberales de las Cortes de Cádiz restituidos.

Como premio a su decisiva participación en la restauración del gobierno liberal, tan sólo recupera, en 1820, su puesto de trabajo en la Secretaría de Estado, hecho que ponía de manifiesto los recelos de los «doceañistas", ya moderados, hacia los liberales exaltados, 0 «veinteañistas" que les habían restituido en el poder. Nada feliz y puesto ello de manifiesto en El Constitucional, intenta fallidamente que le nombren diputado por Cádiz y al no lograrlo se resigna a ocupar su antiguo puesto en Madrid. Por esta época habian nacido las sociedades patrióticas y Alcalá Galiano se afilia a la de los "Amigos del Orden", que se solía reunir en "La Fontana de Oro" donde se hace famoso con sus intervenciones de orador brillante e incisivo, muy influido por las teorías de Benjamin Constant a la vez que amante de la libertad al estilo inglés, disertando sobre asuntos generales de gobierno tanto como de política y cautivando la

44 Se publica de 25 de enero a 26 de mayo de 1829: C. García Barrón: La obra crítica y literaria de don Antonio Alcalá Galiano, Biblioteca Románica Hispánica. Madrid, 1970, pág. 21. 
atención y los ánimos del auditorio 45. Desde La Fontana, volvió de nuevo el orador gaditano a ayudar a los doceañistas en su lucha por conseguir de Fernando VII la sanción de leyes que rechazaba y esta vez sí le premia el gobierno y le nombra intendente en Córdoba en 1821 donde sirvió su empleo y en dos ocasiones, interinamente, el gobierno político hasta que fue elegido como diputado por Cádiz en las Cortes de 1822, regresando así a Madrid.

Desde su escaño en las Cortes, se puso al lado del débil ministerio no sin criticar sus actuaciones anticonstitucionales y reclamó apasionadamente la unión de los liberales contra el peligro francés tomando las dimensiones de hombre grande que ya definitivamente le caracterizaron durante toda su vida. Sus actuaciones violentas contra los desvios de la Constitución culminaron con un acto definitivo que le conllevaría su primera emigración forzosa, a Inglaterra y Francia, durante diez años. Este acto, insólito en la historia de España, consistió en declarar demente temporalmente al rey Fernando VII, ante su negativa a abandonar Sevilla para trasladarse a Cádiz frente al avance de los "Cien mil hijos de San Luis» que, al mando del duque de Angulema, entraban en España enviados por la Santa Alianza europea para restituir al rey en sus poderes absolutos 46 . La declaración de incapacidad moral del rey y su traslado forzoso a Cádiz si bien se trató de una decisión aprobada por las Cortes, fue el diputado Galiano quien se atrevió a proponerla públicamente 47 , por tanto, restituido Fernando VII en su poder absoluto, y ante la dura represión que emprendió contra los liberales, Alcalá Galiano junto con otros españoles afectos al gobierno constitucional pasaron a formar parte de los cientos de exilados liberales que tuvieron que acoger Francia e Inglaterra.

En general, a Francia fueron los doceañistas, que vivieron relativamente bien $e$, incluso, algunos muy bien, y a Inglaterra fueron los veinteañistas que vivieron casi todos bastante mal por el alto nivel de vida de Inglaterra y sobre todo los que intervinieron en la declaración de incapa-

45 "La Fontana de Oro", rehabilitada hoy día, se encuentra ubicada en la calle Victoria de Madrid. En estilo novelado nos describe Benito Pérez Galdós, en su famosa obra La Fontana de Oro, algunas actuaciones del joven tribuno y los temas que en ella se debatían.

46 Sin embargo, abandona los masones al proponerse en una sesión el acabar con la vida del rey y su familia: Memoria, Tomo XXXXIV, pág. 239

47 La declaración de incapacidad del rey, en la sesión de las Cortes del día 11 de junio de 1823, está descrita en la pág. 272-286 del tomo 1 de la Antología de las Cortes de Cádiz de 1821 a 1823, compuesta por Martínez Yagües, por encargo del Excmo. Presidente del Congreso de los Diputados. Madrid, Imprenta Valentín Tordesillas. 1914. 2 vols. $Y$ en el A(rchivo) $H$ (istórico) N(acional), Sección Consejos. Leg. 6.305 
cidad del rey, al condenárseles a pena de muerte y confiscación de todos sus bienes en España 48. Alcalá Galiano llega a Londres con su amigo Angel Saavedra, tras pasar un tiempo en Gibraltar, el 28 de diciembre de 1823 y como otros exilados llegados antes que él, se instala en el barrio londinense de Somers Town constituyendo con Argüelles, Istúriz, Valdés y otros la facción teórica que no participaba activamente en las conspiraciones y que Alcalá Galiano denominó abreviada España constitucional, mientras la facción activa dividida en dos banderías, la de Espoz y Mina y la de Torrijos, se asienta próxima a ellos, manteniendo una actividad beligerante constante.

En Londres vivió Galiano, con su hijo y su anciana tía, siete años de su vida llena de privaciones económicas, pues teniendo in mente la intención (que luego no llevó a cabo) de escribir un libro sobre la vida de Riego y los hechos de la revolución, en el que pensaba manifestar sus reticencias contra el gobierno inglés por la culpa que él creía que había tenido en la caída del gobierno constitucional español, optó por no aceptar los subsidios que sus compatriotas recibieron del gobierno inglés ${ }^{49}$. Sobrevivió, pues, con sus clases particulares de lengua y literatura española a ingleses y la publicación de artículos sobre asuntos políticos y literarios y, como hemos visto, por el nombramiento como catedrático de español en la nueva Universidad de Londres ${ }^{50}$. En el aspecto social impartía clases, junto con otros emigrados, en el «Ateneo Español» que se creó para la enseñanza gratuita a los hijos de los exilados y en el aspecto político abandonó la participación activa, aunque sí prestó su apoyo intelectual si venía al caso, como por ejemplo con ocasión de la muerte del rey de Portugal, Juan IV, y la proclamación de una constitución en aquel reino, suceso que provocó la marcha de algunos emigrados a Portugal y las esperanzas de los restantes en Inglaterra, hasta el punto de que Alcalá Galiano, designado como portavoz de su grupo, escribió una carta para el The Times donde aseguraba a los ingleses que el pueblo español que-

48 El 30 de julio de 1826, la justicia española absolutista les condenaba a pena de muerte de garrote, a los costes del proceso y confiscación de todos sus bienes. AHN, Sección Consejos, leg. 6.305.

49 A. Alcalá Galiano: Apuntes... pág. 21. y V. Llorens, Liberales y románticos..., pág. 50, donde nombra también a otros personajes políticos que no aceptaron ayuda: Argüelles, Valdés, Istúriz, Zulueta, Espoz y Mina...

50 El ilustre profesor cuenta en su autobiografía cómo mejoró su situación económica con la cátedra, por la que recibía doscientas libras esterlinas (20.000 reales de vellón) que uniendo a sus clases privadas y sus trabajos escritos le permitieron una vida más desahogada hasta su marcha a Francia. Apuntes... pág. 21-22 
ría una constitución liberal y que Mina era muy bien considerado en España, con la idea de preparar la opinión pública a ver con buenos ojos cualquier acción para restablecer la libertad en España. No adelantó nada la suerte de los que marcharon a Portugal y los españoles continuaron con sus actividades cotidianas e, incluso, muchos cambiaron su residencia de Somers Town por la isla de Jersey donde la vida era más barata 51 .

No acaba aquí el periplo europeo del autor, el rey Luis Felipe es coronado en Francia tras la revolución burguesa de 1830 y el horizonte se ilumina para los liberales españoles esperanzados con lograr su ayuda para derribar a Fernando VII. Renacen las esperanzas y comienzan los preparativos de marcha, teniendo Alcalá Galiano una activa intervención que no pasó desapercibida para la Embajada española en Londres donde se seguian perfectamente sus pasos, asi como los de los principales revolucionarios:

"Galiano ha regresado aqui estos últimos días de París. Se zuzurra (sic) entre ellos que ha venido a publicar en estos periódicos algunos artículos contra el Gobierno de S.M. de tal especie que los gazeteros (sic) franceses no han querido darles cabida en sus diarios, ni aun el constitucional que se ha negado también porque ha temido comprometer al actual Gobierno Francés con las naciones extranjeras publicando artículos que producirían este efecto $52 .$,

También el gobierno francés socorrió a los exilados aunque en menor cuantía que el inglés. En París Galiano se entrevista con su admirado Constant buscando respaldo para la defensa de la Constitución, pero los franceses, cautos, no se deciden a dar tan importante paso, por lo que Galiano saldrá profundamente decepcionado. Su estancia transcurre con aún más privaciones que en Inglaterra esperando poder entrar en las sucesivas amnistias que se iban publicando en las que los que intervinieron en la declaración de incapacidad del rey nunca estaban comprendidos, pero allí se reúne con su amigo el duque de Rivas, con el que estrecha aún más su amistad y se marchan a vivir juntos a Tours. En esta ciudad permanece hasta 1834, año en que ya habían vuelto a España prácticamente todos los emigrados políticos menos el citado grupo de los que votaron la destitución del Rey en Sevilla o dirigieron intervenciones armadas contra él. La última amnistía, en febrero de 1834, generosa con los liberales debido a la necesidad de apoyo de la reina María Cristina para man-

51 V. Llorens: Liberales y románticos: una emigración... pág. 64. Y A. Alcalá Galiano: Apuntes... pág. 20-23

52 A.H.N. Sección Estado. Leg. 5.483 
tener la corona para su hija Isabel frente al pretendiente don Carlos, permite volver a Alcalá Galiano con su hijo y su anciana tía.

Con la colaboración de su hijo, reanuda su actividad literaria desde El Observador y El Mensajero de las Cortes considerados de corte liberal moderado y de nuevo es elegido diputado por Cádiz sorprendiendo por sus conocimientos y energía desde el primer día que se dirigió a los diputados desde su escaño. Pero lo que no esperaba el ilustre gaditano era el cambio político que se había producido durante sus once años de destierro. No todos los que habian gobernado durante el periodo de la «década ominosa" eran unos ineptos, procedian muchos de ellos de las filas de los afrancesados, aunque estaban divididos entre los que buscaban una conciliación y una reforma del gobierno y de la hacienda y los que se negaban a todo cambio y deseaban suprimir definitivamente a los liberales. Finalmente se habia impuesto una clase moderada que se relacionaba bien con los otros grupos de poder como los industriales, comerciantes y banqueros.

A la cabeza del gobierno figuraba el viejo liberal, ya conservador, Martínez de la Rosa con su Estatuto Real y frente a él se alzaba el grupo de los nuevos liberales exaltados que querian volver a la Constitución de 1812 y que, finalmente, lo hicieron caer con el triunfo de su revolución. En el nuevo gobierno de Mendizábal, por entonces amigo de Galiano (situación aleatoria durante toda su vida), es nombrado ministro del Consejo Real de España e Indias en la Sección de Marina. Pero en esta fase de su vida empieza a encontrarse inadaptado en su carrera política, no consigue que sus discursos unan a las distintas facciones liberales y empieza a mostrar una actitud más moderada, manifiesta en la recomendación de limitar el número de electores y no hacer el voto universal, apartándose así de los principios de la Constitución de 1812 -con la que acabará rompiendo-, lo que provocó el rechazo por parte de los nuevos exaltados, el recelo de los moderados y el calificativo de «apóstata». A la caída de Mendizábal alcanza la jefatura del gobierno Istúriz que organiza un breve ministerio moderado en el que Alcalá Galiano ocupa la cartera de Marina, pero en breve el gobierno cae por efecto de un pronunciamiento y Alcalá Galiano huye a Francia de donde vuelve en noviembre de 1837, catorce meses después, tomando asiento en las Cortes y habiendo jurando la nueva Constitución de corte moderado, desde Pau.

Desde su escaño presenta una actitud ya claramente moderada atrayéndose las iras de los contrarios y en su vida privada, una vez más, reorganiza sus actividades intelectuales escribiendo en el Correo Nacional 
y en La España y fundando, en 1839, El Piloto con Donoso Cortés. Su presencia se registrará en todos los eventos culturales que se produzcan en la capital del reino, ya como parte de la junta directiva del recién fundado Ateneo de Madrid, ya como colaborador de prestigio en numerosos diarios y revistas. En el Ateneo ocupó la cátedra de derecho político-constitucional desde la que impartió sus Lecciones de derecho político 53 (cursos 1838 a 39; 1839 a 40; y 1843 a 44) que se han designado como la base del derecho político-constitucional español debido a que hasta entonces esta disciplina se aplicaba acudiendo a textos extranjeros, como el Curso de política constitucional de Benjamín Constant, y a otros textos nacionales anteriores no tan completos. En cuanto a su actividad literaria, además de muchos artículos en contra de los desórdenes y en defensa de la moderación y la ilustración, pronunciará una serie de conterencias en el Ateneo recogidas en su Historia de la Literatura española, francesa, inglesa e italiana en el siglo XVIII 54 , y traducirá su obra magna, la Historia de España del inglés Dunham, añadiendo la parte correspondiente al reinado de Isabel II. Aún tendrá que soportar otra emigración a Francia en 1841, al verse implicado en la insurrección de las Vascongadas, de donde vuelve en 1843 encontrándose sin asiento en las Cortes y sin trabajo.

Le ofrecen entonces un puesto insólito en su carrera en España: director del colegio San Felipe en Cádiz, a donde marchó despechado de los moderados y aguantó un curso, dejando un interesante discurso de cierre de año escolar a su salida de él, en el que aboga por reducir la variedad y multiplicidad de los estudios en favor de la especialización 55 , y se incorpora a las Cortes como diputado por Madrid siendo en 1845 nombrado senador vitalicio jurando la constitución de 1845, más conservadora que la de 1837.

Todavía sale algunas veces más al exterior, aunque ya de forma oficial y pacífica. La primera será en 1851 designado como ministro plenipotenciario en Lisboa, cargo en el que deja su impronta de hombre culto y de

53 A. Alcalá Galiano: Lecciones de derecho político. Estudio preliminar de Angel Garrorena Morales. Centro de Estudios Constitucionales. Madrid, 1984.

54 A. Alcalá Galiano Historia de la literatura española, francesa, inglesa e italiana en el s. XVIII. Imprenta de la Sociedad Literaria y Tipográfica. Madrid, 1844.

55 Discurso pronunciado después de la aistribución de premios en los exámenes públicos y generales de los alumnos del Colegio de San Felipe de Cádiz. Celebrados al fin del curso de 1843, por el Excmo. Sr. D. Antonio Alcalá Galiano, Regente de los estudios de dicho Colegio. Cádiz, 1844. 
bien hacer entre las más altas representaciones del país vecino, reintegrándose de nuevo a España, al volver Espartero al gobierno, y decidir Alcalá Galiano que no deseaba representar a España bajo el mandato del general. En 1858 es destinado como embajador primero a Turín y de nuevo a Lisboa y a su vuelta a España, ya definitivamente, reanuda su trabajo en las Reales Academias de la Lengua 56 y de Ciencias Morales y Políticas, de la que había sido nombrado miembro en 1859, y en el Ateneo, e ingresa en la Academia de la Historia, en 1863, y continúa su labor literaria escribiendo sobre todo en La América de dónde luego, su hijo Antonio, recopilará sus artículos para confeccionar sus Memorias y publicarlas póstumamente.

En 1865, cuando casi cumplía los 76 años, obtiene por fin el puesto de relevancia en el gobierno que deseó toda su vida y él creía que merecía. El gobierno conservador de Narváez le nombra para la cartera de Fomento e Instrucción Pública, macroministerio que entre otras atribuciones incluía en aquellos tiempos la organización administrativa de la Universidad. Este sería su último puesto y le costaría la vida, muriendo de una apoplejía en pleno consejo de Ministros, cuando se consideraban los graves sucesos de "La noche de San Daniel» 57.

\section{Alcalá Galiano y el pensamiento en Gran Bretaña: utilitarismo y liberalismo en la Inglaterra del siglo XIX}

En los momentos que Alcalá Galiano llega a Inglaterra, la teoría filosófica más innovadora era la de Jeremy Bentham, es decir, el «utilitarismo», que ya él conocía y admiraba desde su juventud en España. Esta filosofía era deducida desde el principio de utilidad, en que todo castigo conlleva pena e incluso mal, y debería ser admitido sólo cuando fuese para evitar un mal mayor. Su posterior fórmula «greatest happiness of the greatest

56 Ingresa en 1847, al mismo tiempo que el duque de Rivas, Durán, Mesonero Romanos, Pastor Díaz y otros, ocupando el sillón «f"

57 En esta aciaga noche, $10 \mathrm{de}$ abril, los estudiantes se manifestaron contra una circular dictada por el Ministro de Fomento, tras la decisión del consejo de Ministros, en que se prohibía a los catedráticos los ataques a la Monarquía y al Concordato, lo que provocó la expulsíon del rector Montalbán al no querer expulsar a Castelar que desde La Discusión había atacado a la Reina en su agresivo artículo «El rasgo". La represión organizada por el ministro de la Gobernación dio como resultado la muerte de algunos manifestantes y muchos heridos. F. Díaz Plaja: La historia en sus documentos, el s. XIX. Madrid, 1954. Pág. 315; y El Pensamiento Español, diario de la tarde. 10 de abril de 1865 . 
number» (la mayor felicidad para el mayor número) sintetiza de manera ingeniosa y original su aportación filosófica, un eslabón muy importante en el paso de la antigua nación basada en la nobleza, la "gentry", los terratenientes y la iglesia anglicana hacia una nueva nación basada en la industria, el comercio, el crecimiento de ciudades marginales y la extensión de otras creencias religiosas y, como colofón, el paso a la democracia.

Frente a Bentham se alzaban las teorías de las dos formas más extremas de entender la política a finales del siglo XVIII. Edmund Burke, defensor de la tendencia políticamente más conservadora, era el representante de la clase noble y aristocrática, en cuanto abogaba por una reforma que no olvidase la herencia del pasado y la tradición. Para él la violencia desatada por los revolucionarios franceses, acarrearía terror, anarquía y despotismo. Por su parte, el otro teórico del radicalismo democrático, Thomas Paine, calificaba a los aristócratas de «banda de rufianes" y defendía los derechos humanos naturales del hombre frente a los que les pudiese otorgar cualquier constitución. Ambas teorias, extremistas, encontraron su punto medio en las de Bentham que defendiendo su "radicalism not dangerous", publicado en 1820, refutaba tanto las teorías de Burke como las de Paine con las suyas propias sobre el utilitarismo. Se convirtió con ello en el ideólogo de la clase media, mientras que Burke simbolizaba el tradicional pensamiento tory post 1688 y Paine recogía las tendencias más extremas del radicalismo democrático. Su filosofía se extendió rápidamente porque además provocaba menos recelos que Paine a los aristócratas, que propiciaba con sus teorias la temida revolución desde abajo, o la de Burke que impedía el ascenso de las nuevas clases medias industriales y comerciales a la defensa de sus intereses económicos y religiosos.

El catecismo de Bentham sobre la reforma parlamentaria, su Plan for Parliamentary Reform, en el que exponía su nueva doctrina sobre el utilitarismo, se publicó en 1817 y se extendió rápidamente aportando conceptos innovadores como elecciones anuales, distritos electorales iguales, amplio sufragio y voto secreto. Posteriormente, en 1828, en su idea de difundir sus teorias entre los futuros dirigentes de los distintos estamentos del país, intervino decisivamente en la fundación de la Universidad de Londres.

Alcalá Galiano, gran admirador de Bentham, contó con su amistad personal en su estancia en Londres, mantuvo correspondencia con él y asimiló y matizó no pocas de sus ideas utilitaristas. "No ha producido el 
mundo novador más atrevido que Bentham" nos dice en su discurso en la Academia de Ciencias Políticas y Morales, en 186458 , cuando ya incluso Bentham había muerto y sus teorías estaban un poco decaídas entre los ingleses dando paso a sus seguidores de la misma escuela Mill, menos radical, o Austin, que además había sido colega de Alcalá Galiano en la Universidad de Londres.

\section{Alcala Galiano y el constitucionalismo británico}

Aunque en prácticamente todas las biografías y ensayos escritos sobre Antonio Alcalá Galiano se sitúa su paso al moderantismo tras cruzar la línea que marca su estancia en Inglaterra, si se leen con atención sus memorias -aún aplicándole el coeficiente de reducción que supone el haberlas escrito entre la madurez y la ancianidad-se podrá observar que nunca fue un hombre violento más que de palabra y que si apoyó activamente movimientos revolucionarios no intervino nunca con las armas. Incluso, en la palabra ya se había moderado antes de salir de España en su primera emigración a Londres. Su paso del liberalismo exaltado al conservador, no sólo se puede achacar, por tanto, a su exilio en Inglaterra y a la calma política autoimpuesta por los años allí pasados pues, ya cuando daba sus discursos exaltados en "La Fontana de Oro», comenzó a producirse un cierto cambio hacia la templanza en su actitud, a la vista del desbordamiento de sucesos populares que provocaban sus palabras y la de otros copartícipes con sus ideas; esto le valió, incluso, la expulsión en una ocasión de la sociedad «Landaburiana» de los comuneros por tacharle de moderado.

Bien es verdad que el sistema inglés, vivido obligatoriamente y estudiado voluntariamente durante juventud y su exilio, parecía hecho a su medida. De su asistencia a las sesiones del Parlamento inglés 59 extrajo muchas de sus ideas respecto a la constitución de las cámaras, sistemas de sufragio y otros aspectos innovadores británicos que luego ex-

58 Del estado de la opinión en Inglaterra en cuestiones religiosas y políticas. Apuntes leídos por don Antonio Alcalá Galiano en la sesión de 8 de marzo de 1864. Academia de C.P. y M. Tomo II, pág. 125-132.

59 Alcalá Galiano nos ha dejado una semblanza de su asistencia a una sesión del Parlamento inglés, donde analiza con gracia, a la vez que rigor, la composición, vestimenta, comportamiento y discusiones de un día, de 1826, de la Cámara de los Comunes, a la que él tenía cierto acceso. «Boceto de la pintura de una sesión de la Cámara de los Comunes de Inglaterra «, en EI Heraldo. (16 de mayo de 1846). pág. 3 y 4 
pondría en sus escritos e intervenciones en el Senado y las Cortes, a su vuelta a España, junto con otras ideas innovadoras resultado de su contacto personal con máximos representantes del liberalismo y utilitarismo ingleses como fueron el político George Canning y Jeremy Bentham, respectivamente.

Encaja perfectamente en su carácter instruido -y erudito en su madurez- y su situación social privilegiada, el horror a la violencia como medio para alcanzar logros sociales y progreso, aspecto, sin embargo, desmentido ampliamente en su juventud exaltada llena de ilusiones de cambio y regeneración para su país e inmersa en un ambiente de injusticias sociales, guerra, insurrección con pérdida de las colonias y rechazo y condena del absolutismo real como consecuencia de las ideas introducidas por la revolución francesa. El cambio de adscripción política y de pensamiento, por tanto, no se fragua en una sola fase de su vida sino que es producto de su observación del sistema liberal inglés de gobierno así como de las ideas utilitaristas que aprende en aquel país que le conducen a pensar que el progreso y la libertad no deben venir de la mano de la violencia, pero al mismo tiempo del bagaje ilustrado de su formación adquirido en su juventud en España así como de la enseñanza grabada en su propia piel con las revoluciones españolas que presenció o en que participó en su patria 60.

Por ende, el alto nivel cultural de Galiano y el gran conocimiento de la lengua inglesa le permitieron incorporarse pronto a los selectos grupos intelectuales que difundian su pensamiento en revistas inglesas 61 . Entre los británicos llegó a tener buenos amigos y gran prestigio y en este ir y venir se enamora aún más de lo que ya lo estaba de "lo inglés" y luego no cejará en sus escritos posteriores de ponerlos como ejemplo de bien hacer y de liberalismo a la vez que moderación. Y, sobre todo, va anotando lo que se puede conseguir sin enfrentamientos y cómo se puede ser liberal siendo moderado, que sería el punto clave de su futuro ideario y cambio de adscripción política en España. Su nombramiento como profe-

60 M. C. Heredia Campos: Antonio Alcalá Galiano como introductor... pág. 84.

61 Si bien es verdad que es difícil localizar todos los artículos que escribió debido a que los diarios y revistas ingleses no tenían la costumbre de citar a sus autores, no lo es menos que debido al magnífico estudio de Vicente Llorens, de las publicaciones de los españoles en revistas inglesas, contamos con una amplia relación de los artículos atribuidos a Alcalá Galiano. Una de las revistas en las que escribió fue The Westminster Review fundada por el filósofo inglés Bentham, que tanto él admiró y tanta influencia tuvo en su pensamiento. Otra revista fue The Metropolitan. Vicente Llorens, "Colaboraciones de emigrados españoles en revistas inglesas (1824-1834)" en Hispanic Review n. ${ }^{2}$ XIX. (1951), págs. 121-142. 
sor universitario de lengua y literatura españolas es bastante significativo de sus actitudes.

Entre sus publicaciones en la "Westminster Review», órgano de los radicales de Bentham, hay artículos sobre la situación política en España en 1826 y 1829. También escribió varios sobre la literatura española del siglo XIX en España para el periódico inglés «The Athenaeum» 62 , aunque esto ya fue en 1834 desde Francia, donde se volcó ampliamente no sólo la producción de los autores líricos y dramáticos del primer tercio del siglo sino también los hechos históricos y movimientos intelectuales que influyeron en sus obras. Finalmente es de destacar las notas que dedicó a un ilustre precedente del pensamiento liberal español, Gaspar Melchor de Jovellanos que publicó en la «Foreign Quarterly Review» en 182963.

University of London y King's College versus Oxford y Cambridge: la formacion de las nuevas clases medias

La Universidad de Londres, hoy University College London (UCL), se fundó en 1826, bajo patronazgo civil, como «nueva» universidad frente a las clásicas, caras y elitistas de Oxford y Cambridge. Basada en la nueva filosofía del utilitarismo de Bentham, no fue fundada por este original filósofo, político y jurista como así se cree; su fundación se debe a un grupo de personalidades liberales británicas entre las que destacan James Mill y Henry Brougham, si bien es verdad que Bentham, que por entonces ya tenía ochenta años, se ha venido considerando el padre espiritual de la nueva universidad no sólo por poner en práctica sus teorías sino porque siempre mostró gran interés por ella e incluso ayudó económicamente a su fundación. Tal vez uno de los hechos que ha contribuido a esta creencia sea el mural existente en la biblioteca de la universidad que representa al arquitecto que diseñó el edificio principal, William Wilkins, mostrando los planos a Bentham ante el escenario del pórtico de la universidad en construcción, sin olvidar un detalle decisivo como es el que su esqueleto, vestido, con la faz de cera y sentado, se conserva en una vitrina de dicha Universidad respetando una de sus últimas voluntades.

62 Los artículos están recogidos en A. Alcalá Galiano: Historia de la literatura del siglo XIX De Moratín a Rivas. traducidos por Vicente Llorens. Alianza Editorial. Madrid, 1969.

63 Este ensayo está traducido y recogido en el tomo LXXXIV de la B.A.E. dedicado a A. Alcalá Galiano, pág.425-439. 
Los principios que rigieron la fundación de la institución fueron absolutamente innovadores con respecto a las tradiciones académicas de las islas. En sus aulas -inauguradas en 1828- se ofrecía educación para un amplio sector de las clases sociales existentes acogiendo tanto a burgueses, comerciantes o nobles como a miembros de distintas creencias, ideologías o razas, y no únicamente a ricos y miembros de la iglesia oficial como era lo habitual en las universidades tradicionales de Oxford y Cambridge, y la formación de sus alumnos se orientó hacia la conjunción de los estudios tradicionales con los modernos preparándoles para que pudiesen ocupar los puestos prácticos que demandaba la Inglaterra de la revolución industrial.

La Universidad de Londres fue, pues, una universidad pionera en muchos aspectos, entre los que destaca la creación de cátedras de lenguas modernas extranjeras, respuesta a la demanda de la enseñanza de estas disciplinas debido a la afluencia de emigrantes en tierras británicas desde el siglo XVIII y a las necesidades de mantener relaciones diplomáticas y comerciales mundiales de un país en expansión desde el siglo XVI. En el caso de la lengua española, se añadía la fuerte motivación que suponía la posibilidad de conquistar los mercadios de las emancipadas colonias de la América española así como participar en la construcción de los nuevos países que requerían técnicos para sus empresas y obras, campos en los que estaba muy interesado el gobierno británico en introducirse.

El cuerpo educativo en el momento de su apertura consistía en veinticuatro profesores, de los cuales cuatro se encargarían de la enseñanza de humanidades correspondiendo a don Antonio Alcalá Galiano la enseñanza de la lengua española y literatura española, constituyéndose, de esta manera, en el protagonista de la iniciación de la cátedra de español en Inglaterra. El programa de asignaturas de la UCL compaginaba el estudio de asignaturas tradicionales como filosofía, lengua y literaturas clásicas, matemáticas, astronomía, economía, etc. con el de otras de aplicación profesional como ingeniería, derecho y medicina. La enseñanza del español, al igual que la de las otras lenguas y acorde con las ideas utilitaristas, fue orientada a su uso práctico hablado y escrito.

A la creación de la UCL, seguirá la del King's College, fundado en 1828 por miembros de la iglesia anglicana con el apoyo del rey Jorge IV, del duque de Wellington y otros importantes personajes eclesiásticos y civiles, y con similares ideas de modernidad a las de UCL. Sin embargo, hasta 1831 no incluirá en su programa de asignaturas el estudio de las lenguas modernas, y aún así el español, junto con el italiano, se impartirán como asig- 
naturas complementarias frente a la enseñanza del francés y del alemán que formaban parte del temario para examen del curso de Instrucción $\mathrm{Ge-}$ neral del departamento de Literatura y Ciencias Generales ${ }^{64}$.

Por oposición podemos mencionar que en la Universidad de Oxford la escuela de lenguas modernas no se crea hasta 1905, aunque la enseñanza del español ya se impartía desde 1858 en la Taylorian Institution como asignatura opcional y con poca asistencia, al igual que en las clases de francés, alemán o italiano. El sistema de enseñanza del español en esta fase inicial, al igual que el de otras lenguas extranjeras, siguió las pautas de la enseñanza tradicional de las lenguas clásicas, latín y griego, es decir, memorizar vocabularios y reglas gramaticales y realizar traducciones escritas sin mucha práctica del lenguaje hablado ${ }^{65}$, sistema que contó con defensores y detractores dentro de la propia universidad por superficial y poco científico en el ámbito de los estudios superiores. La enseñanza de las lenguas extranjeras en la Universidad de Oxford discurrió de forma mortecina hasta su reforma en las últimas décadas del siglo XIX.

En la Universidad de Cambridge la capacidad de adaptación a las nuevas necesidades es incluso menor. No consta que se inauguren estudios y exámenes de lengua española, a la vez que de lengua portuguesa, hasta 1891, siendo el primer profesor de español que se conoce el Dr. James F. Kelly en 1905, con categoría de "Lecturer" 66.

Con la influencia de las teorias utilitarias, el estudio de las lenguas en la Universidad de Londres, fue enfocando hacia la práctica de la lengua y no a su dominio científico, pues se consideró por sus directores que

64 M. Gallardo: aintroducción y desarrollo de la enseñanza de la lengua española en King's College de Londres; algunos aspectos y figuras relevantes", en Association for Contemporary Iberian Studies. Spring (1994). pág. 10-15.

65 M. Gallardo: «The theaching of spanish as a foreing language at the University of Oxford. Fernando de Arteaga y Pereira and his practical spanish, a grammar of the spanish language (1902)" en History of Linguistics 1996, vol.2. Ed. D.Cram, A.Linn, E.Nowwak, Amsterdam, (1999), pág. 227

66 "Lecturer" es la categoría inferior de profesor en el rango universitario. La información sobre los estudios de español en Cambridge ha sido facilitada por Ms. Neale (doña Coral Garcia Vera), Senior Secretary del Spanish and Portuguese Dept. de la universidad, que además nos ha brindado la noticia singular de la donación en 1917, por alguien desconocido, de 10.000 libras para dotar una escuela de Español a cargo de un «Reader" (similar a "agregado" en España, superior a "lecturer" e inferior a "professor» o catedrático). Posteriormente, en 1933 se establece la cátedra de español siendo el primer catedrático John B. Trend. 
aquella era la base de la enseñanza, el que la lengua fuese útil para las relaciones entre paises, teniendo como principal objetivo enseñar a escribir cartas comerciales, por lo que no se exigía del alumno ningún conocimiento sobre la materia.

\section{Alcalá Galiano lingüista y docente}

La cátedra de español, o de "Spanish Literature» como era su denominación correcta, la alcanzó don Antonio Alcalá Galiano en reñida oposición -en la que fue decisivo su alto conocimiento de la lengua inglesa-, con otros liberales españoles refugiados en Inglaterra como Pablo Mendíbil -que luego obtendría la cátedra de español en King's College en 1831 - J José María Jiménez de Alcalá 67 , que sustituiría a Mendíbil en su puesto a su pronta muerte. Todos ellos ya impartían clases de español en el exilio para ayudarse económicamente y en el caso de Alcalá Galiano era además muy conocido y apreciado en los círculos intelectuales ingleses además de contar con la amistad personal y apoyo de Bentham, que le escribía esta carta: «My worthy old friend, [...] I should reason on every point of view intellectual as well as moral, to felicitate myself on the acquaintance I had made with you; and as to the function belonging to the particular situation in question I never heard nor do I expect to hear, of any person who so far as I am capable of judging is qualified and desposed to enter into competition with you. [...] 68

Las clases de don Antonio Alcalá Galiano, a pesar de su dedicación contaron con muy pocos alumnos y transcurrieron con distinto grado de aprovechamiento por parte de estos. Nuestro profesor se lamenta de estar causando un gasto a la Universidad que no se veía compensado con los resultados. Mantuvo sus clases, por tanto, durante los cursos de 1828 a 1830, año en que en el mes de julio renuncia a su cátedra (incidiendo en su decisión las disputas entre la dirección y los profesores por la difícil marcha de la institución y sentirse molestado en su dignidad), mientras otras lenguas modernas más arraigadas como francés, alemán o italiano se mantenían. El relevo en las clases de español lo tomó el King's Colle-

67 M. Gallardo Barbarroja: «Antonio Alcalá Galiano y la enseñanza del español en la Universidad de Londres". Donaire, n. ${ }^{9} 5$. (1995). pág. 29.

68 Fragmento de carta de Jeremy Bentham a Alcalá Galiano del 2 de febrero de 1832, publicada en el artículo de M. Gallardo: idem pág. 31. 
ge en 1831 , con un éxito reducido, igualmente, pero capaz de mantenerse hasta 185469 .

No dudamos de los motivos académicos de Alcalá Galiano para dejar sus clases; el orgulloso exilado, aunque muy bien aceptado en los medios intelectuales ingleses nunca estuvo dispuesto a admitir una duda sobre su persona o trabajo, pero también concurre en esta ocasión que muy próxima a la fecha de su carta, de 7 de julio de 1830 , se producía en Francia la Revolución de julio iniciando el reinado del duque de Orleans, como Luis Felipe I, y comenzando la "edad de oro de la alta burguesia», que inmediatamente puso en marcha las ilusiones y los traslados de los exilados españoles de Inglaterra a Francia. De hecho nuestro ilustre exilado ya se encontraba en Francia el 11 de agosto, a donde había llegado con "otros cuarenta revolucionarios" 70 .

Alcalá Galiano y la cultura española:

discurso de toma de posesion de su catedra *

Toda la armazón teórica de la lección inaugural de Alcalá Galiano se sustenta sobre dos ejes: el primero, es demostrar la importancia de la cultura española en el contexto europeo, de lo cual se infiere la necesidad de adecuar la marcha política y económica de su país de origen a los modelos más avanzados de Europa. En este sentido Alcalá Galiano, no difiere mucho de una larga tradición de pensadores que arranca en la llustración y que se hace particularmente evidente en el convulso período que va entre la invasión napoleónica y la regencia de María Cristina, momento en el cual todos los «liberales» españoles se ven obligados a optar no sólo por una facción política interna sino también por alguno de los dos grandes polos de atracción cultural que eran a la sazón, el británico y el francés.

69 M. Gallardo: idem. pág. 32

70 A.H.N. Sección Estado. Leg. 5.483

* Para la fase crítica de este trabajo, que aquí se inicia, hemos contado como obra básica con la monumental Mistory of Spanish Literature del americano George Ticknor, publicada en inglés 1849 y traducida como Historia de la literatura española, traducida al castellano, con adiciones y notas críticas, por don Pascual de Gayangos, individuo de la Real Academia de la Historia y don Enrique de Vedia. 4 tomos. Madrid, Imprenta y Estereotipia de M. Rivadeneyra. 1865. Ticknor, estudio en Europa de 1815 a 1819 y luego fue profesor de lengua y literatura española en la universidad americana. En su obra, primer estudio de carácter general de las letras españolas, nos introduce en la percepción que se tenía en el extranjero de la literatura española. 
Sin embargo, en nuestra opinión lo más interesante de este discurso es la insistencia de Alcalá Galiano en conectar el español y por ende toda la cultura hispánica, con una tradición clásica que él interpreta en el sentido del mejor racionalismo de raigambre ilustrada. Dicho de otra manera, mientras que una parte sustancial de la cultura europea llamada «prerromántica» mira hacia el sur peninsular como una especie de vestigio arcaico del oriente 71, Alcalá Galiano intenta oponerse al estereotipo. Un estereotipo que, no debemos olvidarlo, había sido propiciado por la amplia difusión que habian tenido en la cultura europea tanto los romances fronterizos o la leyenda negra, uniendo en un solo conjunto la inquisición, el tratamiento de las minorías musulmana y judía ${ }^{72}$, y el pasado árabe de la Península tal como aparece en las obras de Casiri y, sobre todo, en la Historia de la dominación de los árabes en España, de José Antonio Conde, publicada a principios del segundo decenio del siglo XIX. Con este bagaje se acepta comúnmente que lo español es el resultado de una mezcla entre occidente y oriente debiendo achacar a la herencia oriental las causas del presente estado (el del siglo XIX) de decadencia en el que se encuentra el antiguo y poderoso solar del imperio de los Ausburgo. Alcalá Galiano, sin embargo, va a alejarse de esta interpretación dominante, la más familiar para el público culto británico, para hacer depender casi exclusivamente lo español de la tradición clásica.

Todo su resumen de la historia de la literatura española es una recreación consciente al servicio de este propósito que entronca, por otra parte, muy bien con las necesidades del emergente nacionalismo decimonónico de origen burgués 73 . Por ello, quizás sea conveniente seguir el hilo conductor que el propio Alcalá Galiano nos ofrece para apreciar la magnitud de esta original selección.

Esta parte del discurso, se abre con una apreciación general sobre las fuentes que han conformado la literatura en español. Los precedentes ára-

71 Cfr.: Edward Said Orientalismo. Madrid, 1993, cap. 2; Maxime Rodinson, La fascinación del Islám. Madrid, 1989, cap. 2; Angel Galán Sánchez, Una visión de la decadencia española, ... Parte II.

72 Cfr. M. Manuela Manzanares del Cirre: Los arabistas españoles del siglo XIX. Madrid, 1982 y el todavía imprescindible y clásico estudio de James T. Monroe. Islam and the Arabs in the spanish scolarship. Leyden, 1970.

73 Cfr.: A. Cirujano y otros: Historiografia y nacionalismo español. Madrid, 1977. Para el marco teórico de los estados-nación, el provocativo estudio de Benedict Anderson: Comunidades imaginadas, el origen y el desarrollo de los nacionalismos. Madrid, 1996; y el sólido estudio dirigido por Eric Hobswaum: La era de los nacionalismos. Barcelona, 1999. 
bes, latinos o judíos se aluden de forma genérica como fuentes de la moderna lengua española. Alcalá Galiano distingue cuidadosamente entre lo que él cree que es el patrimonio común, lo hispánico, fundamento de la nación, y la expresión más acabada de este pueblo que es la lengua autóctona 74 . Pasado ese momento Alcalá Galiano empieza a examinar los precedentes antiguos. Se oculta cuidadosamente toda la posible influencia oriental que viene de la mano de fenicios y cartagineses a través de mitos como el de Tartessos que había ocupado un lugar no despreciable en la historia de la cultura de los siglos XVII y XVIII 75 y se alude directamente al latín como primer origen de la cultura hispana. La herencia de Roma, adquiere en Alcalá Galiano un carácter político cultural que hace imposible una interpretación "purista» de los precedentes latinos, puesto que en efecto no se trata de acudir sólo a la larga nómina de escritores latinos de origen hispano para señalar la obvia filiación entre una lengua y la otra, sino que el ilustre exilado alude también a las glorias políticas que Roma ofreció a España. Así Adriano, Trajano o Teodosio, son el pórtico necesario para mencionar de forma más o menos rápida a autores de géneros muy diversos como Julio Higinio, Séneca, Lucano, Marcial, Quintiliano o el agrónomo Columela ${ }^{76}$. En este punto, Alcalá Galiano parece ser especialmente deudor de una de las mejores obras que produjo la llustración española, la Bibliotheca Hispana Vetus, de Nicolás Antonio, compendio que por lo demás fue ampliamente utilizado por toda la cultura europea de la segunda mitad del siglo XVIII y a lo largo del siglo XIX 77 .

Acto seguido, Alcalá Galiano alude a una idílica herencia musulmana, pero no menciona ni un sólo autor de la amplia panoplia andalusí. Si Al Andalus se reduce a tres líneas vagas que parecen más pensadas para satisfacer al auditorio británico que producto de la convicción propia, Sefarad recibe un tratamiento aún más fugaz. Alcalá Galiano alude a la rica

74 Ctr. para el valor de las lenguas como sustrato del que emerge una expresión nacional diferente, por ejemplo, José Antonio Maravall: Antiguos y modernos. Madrid, 1998. Págs. 113 y ss. o Jon Juaristi, El bucle melancollico. Madrid, 1999.

75 Manuel Alvarez Marti-Aguilar: Tartessos en la historiografía española, siglos XVI al XX. Málaga (en prensa).

76 Cfr.: el siempre útil, aunque desfasado desde el punto de vista metodológico, estudio de Antonio García y Bellido: La España del siglo I de nuestra era, Madrid, 1956, para medir la categoría de algunos de los mencionados.

77 Para calibrar la importancia de esta obra excepcional, sobre la que existe una bibliografia prácticamente inabarcable, puede acudirse a los certeros juicios de Antonio Mestre en la síntesis que hizo para el tomo correspondiente a la llustración de la Historia de España de Menéndez Pidal. 
literatura de los hebreos hispanos medievales sólo para reclamar su hispanidad frente a un catedrático de Hebreo y colega suyo de claustro que la habia incluido en la literatura en hebreo con carácter genérico. Tal reivindicación de la hispanidad de los sefardíes no se ve acompañada, sin embargo, de ninguna mención concreta o de ningún rasgo que le parezca especialmente destacable de esta parte de nuestro pasado.

Finalmente, Alcalá Galiano se enfrenta al origen del español. Para él la primera pieza literaria de la nueva lengua romance es el poema del Mío Cid, por razones que se nos escapan no acude a los dos modelos de poesía épica en lengua vernácula cuyas analogías son más evidentes con el poema del Mío Cid. Ni la Chanson de Roland, ni el poema de Beowulfo ${ }^{78}$, son aludidos. En efecto, el carácter de gran poema épico nacional parece no interesar al nuevo catedrático de la Universidad de Londres aunque se apoya en la opinión de su compatriota Blanco White para defender la calidad literaria de la literatura medieval. En su conjunto la literatura medieval aparece en Alcalá Galiano como una especie de etapa de aprendizaje que no va a ser culminada hasta que el humanismo italiano vivifique con sus aires clásicos la lengua española, aunque existe una evidente escala de progreso a medida que la edad media se va acercando más al siglo XVI. Las Partidas, el código legal que más atención había recibido en la erudición española de principios del siglo XIX ${ }^{79}$, le merecen una alta consideración por la elegancia del lenguaje. Las Fábulas del Conde Lucanor y sobre todo las Coplas de Jorge Manrique son, en la opinión de Alcalá Galiano, cumbres de este período. Fernán Gómez de Ciudad Real y el Laberinto de la fortuna de Juan de Mena, son igualmente citados en este escogido elenco de aquellos que hicieron progresar la lengua española.

Remata la exposición del período trayendo a colación la observación de su amigo, y admirado en su juventud, el poeta Quintana, quién compara a los escritores líricos -de cuyas composiciones salva los romancescomo algo, si bello, ya trasnochado e inútil. Ninguna mención a La Celestina o a la Tragicomedia de Calixto y Melibea - cosa que sí hará en estudios posteriores sobre la literatura española, ya en España-, que se podría interpretar por la confusión de valores y el escepticismo manifiesto de la obra que conducen a sus personajes a un individualismo y crisis de

78 Poema épico anglosajón, temáticamente perteneciente a la antigua tradición germánica y admitida su composición entre los años 770 y 750 .

79 Baste pensar en la extensa obra de Martínez Marina para comprender la importancia de las Partidas 
ideales que a Alcalá Galiano no le interesaba resaltar fuera de su pais, sin embargo Calixto y Melibea era bien conocida e, incluso, responsable de la entrada en aquel país de la palabra «comedia» (commedye) que alli se define como semejante al interludio inglés.

El verdadero nacimiento del español, sin embargo, hay que buscarlo en el cambio que supuso el siglo XVI y el Renacimiento bajo los reinados de Carlos V y Felipe II y las relaciones que se establecen con la culta Italia por medio de las guerras de los primeros Austrias. La literatura española recibe tal impulso que su inercia le hará alcanzar los reinados de los Felipes siguientes ${ }^{80}$. Para el docto profesor de lengua española, el renacimiento de los estudios clásicos, el retorno a las fuentes y la traducción de la Biblia Polyglotta, muestran cómo de integrados están los españoles en la nueva corriente denominada «Clásica» en Europa, para lo que elige a los humanistas y gramáticos Arias Montano, Abril, Nebrija, Vives y Sánchez de Brozas como los más eminentes iniciadores del estudio de las lenguas clásicas, y a los historiadores Hurtado de Mendoza y Mariana, a los que aunque cita rápidamente él admira profundamente como renovadores de un estilo de hacer historia ya consagrado en la Roma dorada de la historiografía clásica de Tito Livio, Salustio o Tácito. Ninguna mención a las grandes figuras de la singular Mística española que fueron San Juan de la Cruz y Santa Teresa, lo que le hubiese obligado a apoyar o criticar la actitud pasiva ante la vida, en tanto que contemplativa y sin libre discusión, de un movimiento genuinamente español, sin olvidar la arraigada convicción británica de la nefasta influencia del catolicismo hispano sobre nuestra capacidad de progreso. Si cita, sin embargo, al gran Fray Luís de León, aunque no precisamente como integrante de este movimiento -del que, además, es considerado un místico no completo-, sino, probablemente, porque la actitud de León estaba en la línea de las clases que pensaba impartir ya que defendió con pasión la lengua castellana como instrumento de cultura frente al uso obligado de las lenguas clásicas para los estudiantes de la universidad. Por tanto, la mística española es un episodio de la literatura española que no le parece adecuado tratar ante el público inglés. Respecto a los poetas, entre los que destaca a Garcilaso, Herrera y fray Luís de Granada, aunque reconoce la belleza de sus obras, justifica su falta de energía y originalidad con la situación religiosa de España en aquellos momentos en que la Inquisición y su censura a los ata-

80 Modesto Lafuente: Historia de España continuada desde la muerte de Fernando VII por don Juan Valera, con la colaboración de don Andrés Borrego y don Antonio Pirala. 6 tomos. Montaner y Simón, Barcelona. 1880. Tomo 1. pág. XXVII 
ques contra las doctrinas del catolicismo tuvieron una gran influencia negativa en el caso de los escritores, al privarles de la libertad necesaria para producir obras literarias o científicas originales, y positivas para el clero que adquirió una importancia inusitada en su papel de directriz de cómo y sobre qué habia que escribir 81.

En resumen, Alcalá Galiano justifica que este siglo, en el que España era una gran potencia, aún contando con magníficas figuras en todas las ramas literarias, solamente pudo profundizar en el campo de la teología y no aportó lo que debía y podía al progreso de otras manifestaciones de la literatura española, máxime si se tiene en cuenta que los siglos XVI y XVII fueron para los ingleses los de Shakespeare, Marlowe y Kyd y otros isabelinos importantes ${ }^{82}$, que, como los españoles, se inspiraron en las fuentes clásicas, aunque el único autor clásico bien conocido por ellos, y presente en su teatro, era Séneca. Tal vez, una buena razón para justificar a nuestros escritores del siglo de Oro, hubiera sido el exponer como aún estando inmersos personalmente en las continuas batallas que mantenía la patria, no dejaron de ofrecer buenas obras incluso desde los campos de batalla, contándose entre ellos a Pérez de Guzmán, Lope de Ayala, Jorge Manrique, Bernal Díaz del Castillo, Boscán, Hurtado de Mendoza (embajador de Carlos V y general), Garcilaso (que acompaña a Carlos V y muere en Túnez), Ercilla (que escribe La Araucana combatiendo), e incluso Cervantes y Lope ${ }^{83}$.

A finales de siglo y principios del XVII, la trayectoria empieza a desviarse de los clásicos y produce una panoplia de buenos escritores que muestran su originalidad aunque al apartarse de los moldes clásicos se aventuran por nuevos caminos con el riesgo de éxito o fracaso que conllevan los experimentos. Aflora un nuevo estilo de novela, la picaresca, entre la que Alcalá Galiano elige el Guzmán de Alfarache como su más tempra-

81 Hay que pensar que las dos obras más difundidas entre el público culto inglés, procedentes de autores españoles en la época en que Alcalá Galiano escribe su discurso son A. Puigblanch, The Inquisition Unmasked. London, 1815 y, por supuesto, la muy influyente obra de J.A. Llorente Historia de la Inquisición Española, París, 1821-1823. Ni que decir tiene que, al margen de una larga tradición antiinquisitorial que venía desde el siglo XVI (Cfr. J.Juderías: La Leyenda Negra, Madrid, 1911; y R.García Cárcel: La Leyenda Negra, Barcelona, 1996), estos dos ilustres liberales, sobre todo el último de ellos, ofrecieron a la intelectualidad europea munición suficiente para reafirmarse en su idea durante una centuria más.

$82 \mathrm{Cfr}$. los clásicos trabajos de: C. Hill: Los orígenes intelectuales de la Revolución inglesa, Madrid, 1977 y, del mismo autor, Some Intellectual Consequences of the English Revolution. London, 1980 y El siglo de la revolución, Madrid, 1983.

83 M Lafuente: Historia de España desde..... Tomo 1. pág. XXVII 
no representante, sin mencionar su predecesora El lazarillo de Tormes, obra bien conocida por los ingleses, traducida ya en 1576 y de gran influencia hasta el siglo XVIII, para pasar rápidamente por el internacionalmente conocido Cervantes, y su máxima obra Don Quixote ${ }^{84}$, y por Lope de Vega en los que no se extiende por dejar esta tarea para su curso.

Ya en pleno siglo, surge un gusto manifiesto por lo oriental. Las creaciones literarias se llenan de colorido, de amores bucólicos, hipérbole y metáforas de raigambre árabe y nombres moriscos tanto en la prosa como en la poesía españolas y esta vez el ilustre español sí está dispuesto a admitir estos signos porque ya no influyen en las raíces de la lengua española ni en los inicios de su literatura ${ }^{85}$, aunque siempre porfiando en la falta de conexión con autores árabes. El siglo XVII es aquel en el cual, para Alcalá Galiano, «España decae en armas y letras» comenzando tras el primer tercio para encontrarse totalmente abatida al final del mismo 86 mientras su vecina Francia despega hacia la grandeza política y literaria con el reinado de Luís XIII. Surgen, no obstante, los nombres de Quevedo, Saavedra o Moncada y en los estudios históricos el de Francisco de Melo, al que califica como el mejor de los historiadores españoles. El mérito principal de Melo era el haber descrito con imparcialidad, algo nada común en su época, los hechos bélicos en los que participó. Su Historia de los movimientos, separación y guerra de Cataluña en tiempo de Felipe $I^{87}$, aunque abarca un periodo muy limitado de la historia de España era considerada como una obra clásica de la historiografía española. Debe pensarse que cuando Alcalá Galiano da su clase inaugural, la historia general de España se limitaba a la obra histórica nacional por antonomasia, la Historia general de España del padre Mariana, que tan sólo alcanzaba hasta los Reyes Católicos, aunque existían diver-

84 Ambas obras, El Quijote y el Lazarillo de Tormes, eran las dos obras del siglo de Oro español mejor conocidas de los ingleses. M.G. Ticknor: Historia de la literatura español... Ticknor las describe, en el caso de la primera, como "El lazarillo es una obra de mucho ingenio, no parecida a ninguna otra anterior». Tomo II, pág. 65; y en el de la segunda: «Obra superior, no sólo á todas las de su época, sino á las de los tiempos modernos, que lleva impreso el sello del carácter nacional...", tomo II, pág. 238.

85 Para la consideración que esta peculiar forma de orientalismo tiene entre los eruditos anglosajones. Cfr.: The Comfort "The Moors in Spanish Popular Poetry before 1600\%. Harverford Essays. Studies in Modern Literature. Harverford, (1909), págs. 273 - 330.

86 A. Alcalá Galiano: "Que el estudio profundo y detenido de las lenguas extranjeras, lejos de contribuir al deterioro de la propia, sirve para conocerla y manejarla con mas aciertom. La España. 5 oct. 1861 pág. 2.

87 Publicada en 1645, con varias reediciones en el mismo siglo y dos más en1805 y 1808 , en Madrid. 
sas adiciones que prolongaban su horizonte cronológico, y para las exigencias de la época estaba escrita con un sentido relacional de los hechos históricos falto de crítica y sobrante de moralizaciones. Este vacio no se cubrirá hasta que aparezca, bien avanzado el siglo XIX, la historia de España de Modesto Lafuente ${ }^{88}$.

Inexplicablemente, y a la vez consecuentemente con su pensamiento sobre la literatura española, vuelve a sufrir, nuestro catedrático, uno de sus «olvidos»: El nombre de Luís de Góngora, el máximo representante del discutido culteranismo español, del culto a la oscuridad, de la introducción, para muchos, del «mal gusto» en la literatura española, y poderoso enemigo de Quevedo, ni siquiera es capaz de pronunciarlo, a pesar de ser bien conocido por los ingleses por las controversias surgidas en torno a él ${ }^{89}$. No hay que perder de vista que su conferencia está orientada hacia mostrar aquellos autores que él considera que tienen una influencia beneficiosa para la literatura española y le dan lustre, razón por la que -aunque promete imparcialidad en sus cursos-, sortea a los escritores que le parecen perjudiciales.

De este mismo siglo, decide elegir como máximo representante a Calderón de la Barca, no sin indicar suavemente que no comparte totalmente la gran admiración que había despertado en "una importante nación", refiriéndose implícitamente a Alemania defensora del dramaturgo español como faro del movimiento romántico. Este episodio merece mención especial pues los ecos de la «querella calderoniana» que Alcalá Galiano, junto con su amigo José Joaquín de Mora, había mantenido, en 1818, en sus inicios literarios, contra Böhl de Faber introductor del prerromanticismo en España, llegaron hasta inglaterra donde la polémica era bien conocida. Alcalá Galiano que en tiempos de la disputa literaria se mostró claramente contrario a la nueva corriente literaria, por apartarse de las formas clásicas en favor de la vuelta a la edad media y al orientalismo, aunque fue suavizando con el tiempo su postura e incluso llegó a aceptarla parcialmente durante su estancia en Londres 90 , nunca llegó a ad-

88 Antes que la Historia de España de Lafuente, se publicaron las de E. de Tapia, F. Gonzalo Morón, E. Chao e, incluso, la de Dunham, pero todas ellas fueron superadas en aceptación -y apoyo por parte del gobierno- con la publicación de la de Modesto Lafuente (1850-1867). F. Lopez "Modesto Lafuente...", pág. 10.

89 M. G. Ticknor, Historia de la literatura... Tomo III, págs. 203-209.

90 Durante su estancia en Londres es justamente cuando el romanticismo inglés se encuentra en todo su apogeo y entre sus temas tavoritos se recogen no pocas de las gestas españolas y sus romances ya cristianos ya musulmanes. Sin embargo, Alcalá Galiano dice en su prólogo a El moro expósito que alnglaterra no consiente, ni casi conoce, la división de los poetas 
mitirlo plenamente como movimiento arraigado en España sino importado y por tanto incapacitado para desarrollarse de una forma original y duradera. No obstante, en esta fase de acercamiento al romanticismo, al redactar el prólogo a la obra El moro expósito de su siempre amigo, el duque de Rivas, hizo un reconocimiento público de la pugna literaria existente entre clásicos y románticos y trató de describir las diferencias entre unos y otros dando a cada cual su mérito pero aunque manifiesta su suave admisión de lo que otrora hubo rechazado con pasión, no se pronuncia por ninguno de los dos contendientes de una forma contundente y tiene buen cuidado de no calificar la obra ni como "romántica» ni como «clásica»

Solís cierra este período y España se sumerge en un mar de tinieblas para su literatura a la par que para su historia. Al ser un periodo más cercano a nuestro conferenciante, su verbo se vuelve más vivo, más implicados sus sentimientos y comienza a exponer sin prisa pero sin pausa los motivos de la decadencia y postración en que se encuentra el país en los tiempos que a él le han tocado vivir, a pesar de las luchas de sus predecesores ilustrados por proporcionarle un porvenir venturoso.

El siglo XVIII sumerge a las letras españolas en la copia de los franceses, producto de la introducción de la rama borbónica en el trono español y la protección real de las letras que se sucede. Sin embargo, este enriquecimiento del ambiente literario viene acompañado de la pérdida del espíritu nacional y la lengua española se corrompe con la intrusión de las aportaciones francesas. Los escritores españoles se dedican a la imitación de los franceses "en sus doctrinas y en su dialecto» hasta el punto que se copiaba a franceses sin valia como hizo Luzán con Le Bossu. Pocos y de regular valía se salvan de esta corriente de la que nuestro ilustre analista, no sin dolor, apenas acierta a extraer al padre Feijoo, al que califica como no muy selecto pero firme y de gran sentido común - cualidad, esta última, de gran valor para nuestro conferenciante como defensor de la sensatez y el justo medio-, que consiguió mantener valientemente su independencia literaria combatiendo la ignorancia y la superstición popular $e$, incluso, ser protegido por Fernando VI de las envidias de sus detractores conformistas con el nuevo régimen absolutista francés.

en clásicos y románticoš. Duque de Rivas: El moro expósito o Córdoba y Burgos en el siglo décimo. Madrid, 1982. Tomo 1 pág. 23. 
Su frente se ilumina al llegar a finales de siglo y hablar del insigne togado Jovellanos con el que además parece identificarse al relacionar los valores que le adjudica que son los que él propugna para el portador de ideales liberales del propio siglo XIX. La trayectoria ilustrada y renovadora por Jovellanos iniciada, se trunca, no obstante, con los graves sucesos de las revoluciones francesas que acontecen en España en el primer cuarto del siglo XIX. Los hombres de letras se dejan atrapar por la política dividiéndose agriamente y volcando sus intereses y disputas en una rama del saber que nunca debió verse mezclada en problemas de otra índole que la defensa de la belleza. Aunque el nuevo Catedrático de Literatura Española proclama que no está evitando describir el talante o valor de sus contemporáneos, lo cierto es que, sin poner en duda que en sus clases hará un tratamiento imparcial de estos contemporáneos, Alcalá Galiano soslaya el tener que señalar ante su público inglés ni uno sólo de sus compatriotas y -salvo la mención que fuera de este contexto ha hecho del poeta Quintana-, deja a su auditorio con la intriga de sus preferencias, concluyendo de esta manera su selecta exposición sobre la literatura española.

Las últimas palabras de su lección inaugural las dedica a expresar la importancia de estudiar lenguas extranjeras, no sólo por su utilidad -motivo ya bastante importante-, sino porque el logro del intercambio de entendimiento entre países produce altos beneficios para estos, más concordia y, a la postre, progreso; esto independientemente de la satisfacción que aporta la aprehensión y el cultivo de la belleza, una de las piedras de toque del ideario liberal de don Antonio Alcalá Galiano que repetirá en buen número de sus conferencias y escritos ${ }^{91}$. En cuanto al halago, obligatorio y no por ello servil, a la institución que le contrata, lo dirige hacia entroncar la creación de la noble e innovadora universidad que inicia su andadura, con lo que se ha dado en llamar el espíritu de los tiempos, frase que compendia las máximas aspiraciones e inquietudes de una generación con ideas renovadoras en un siglo en profunda transformación.

\section{CONCLUSIONES}

Finalmente quizás convendria resumir brevemente el mensaje de don Antonio Alcalá Galiano a un seguro selecto público que, si perte-

91 A. Alcalá Galiano: "Que el estudio profundo...", pág. 3. 
necía a la organización de la universidad, estaría interesado en comprobar en qué medida su deseo de contar con profesores de excelencia se veía satisfecha. Si eran españoles exilados, el interés podía ser doble no ya sólo por la enseñanza que podían extraer de la lección en sí misma ante las pocas oportunidades de disfrutar de disertaciones tan eruditas sobre la madre patria, sino por la satisfacción que debían sentir al verse -en la persona de Alcalá Galiano- aceptados en una institución liberal, pionera en sus métodos de enseñanza y captación de alumnos, procediendo de las filas de los emigrados. A todos ellos también les podía mover la curiosidad por ver el tratamiento que el noble gaditano daba a los elegidos para su curso de literatura, a los participantes en el nuevo movimiento romántico y, sobre todo, a sus contemporáneos que se alistaron en las filas político-literarias emergentes de los sucesos españoles. No cayó en tan fácil trampa y el nuevo catedrático se limitó a bordar su conferencia en torno a las ideas fundamentales que, con sus "olvidos", en unos casos, y vaguedades, en otros, es seguro que llevaba perfectamente preparada. Estas ideas fundamentales, fueron:

- Reivindicar la belleza del español y su importancia, otrora, en la formación de la conciencia nacional. Debe pensarse en la estrecha asociación que existe entre capacidad de progreso y racionalidad en el desarrollo de las naciones y la lengua de las mismas. Una lengua en pie de igualdad con el resto de las lenguas europeas de las grandes naciones era un claro indicio de que los males de España tenían remedio;

- Ignorancia de todo poeta, dramaturgo o prosista en cuya obra se manifestase el mal gusto, falta de originalidad, deterioro de la lengua y el pensamiento españoles y, en fin, de todo aquello que conllevase el estigma de atraso para su patria;

- Inflexibilidad en no conceder en la formación de la lengua española influencias decisivas orientales, ya árabes ya hebreas, identificadas con falta de progreso, aunque no sin reconocer sus enriquecedoras aportaciones;

- Defensa de la integración de España mediante el conocimiento de su lengua y su cultura nacional entre los países extranjeros de primera línea así como la importancia de su aportación al entorno europeo y al mundo; 
- Interés práctico del estudio del español por su aplicación comercial para una Inglaterra industrial que habia perdido sus colonias americanas y estaba necesitada de conquistar mercados en las colonias españolas emancipadas; y

- Rechazo de la dependencia de la influencia francesa en la literatura española cosa que no dejó nunca de preocuparle, y seguir manifestando en sus artículos más tarde en España, pues en realidad acabó reconociendo que el movimiento romántico no había conseguido calar en España ya que de procedencia alemana o francesa era un movimiento importado a España y no bien asimilado 92 .

92 Para consultar sobre el efracaso del movimiento románticom, E. Allison Peers: Historia del movimiento romántico español, 2." ed. Tomo II. Pág. 9-76. Madrid, 1973. 